\title{
CONCEPTUAL DESIGN STUDY \\ FOR THE \\ HCRF DIRECT CONTACT HEAT EXCHANGER MODIFICATION
}

\author{
E. F. Wahl
}

Published June 1984

Wahl Company

2338 Dana Court

Claremont, California 91711

\author{
Prepared for EG\&G Idaho, Inc \\ Under Subcontract No. C84-110284 \\ and the U.S. Department of Energy \\ Under Contract No. DE-AC07-76ID01570
}




\section{ABSTRACT}

The conceptual design of sieve trays for modifying the HCFF direct contact heat exchanger was developed as follows. The models of the prior work, EG\&G subcontract Na. K-7752, were extended and modified so the predicted heat transfer coincided with the experimental data of the $60 \mathrm{KW}$ Raft River tests conducted by EG\&G. Using these models, a hole diameter of 0.25 inches and a hole velocity of $1.3 \mathrm{ft} / \mathrm{sec}$ or greater was selected to accomplish the required heat transfer while minimizing mass transferred to the geothermal fluid. Using the above information, a conceptual design for a sieve tray column was developed. It was determined that the column should operate as a working fluid filled, working fluid dispersed column. This is accomplished by level control of the geothermal fluid below the bottom tray. The dimensions and configuration of the trays and downcomers, and the number of holes and their diameters is summarized in Wahl Company drawings 84144001 and 84144003 submitted with this report. The performance of this design is expected to be $12,000 \mathrm{lbs} / \mathrm{hr}$ of geothermal fluid for single component fluids and 11,800 to $12,0001 \mathrm{bs} / \mathrm{hr}$ for mixed fluids at a working fluid flow rate of $71 \%$ of the geothermal fluid flow rate. The flow rate limit of the geothermal fluid will vary from 9800 to $13,0001 \mathrm{bs} / \mathrm{hr}$ as the ratio varies from $83 \%$ to $62 \%$. 


\section{CONTENTS}

Introduction 1

Selection of Hole Diameter and Velocity 2

Mechanistic Interpretation of Selection 3

Dther Design Strategies. 4

Flooding Limitations

Upflow Flooding 5

Downcomer Flooding 12

By Upflow Flooding Limit - High Rf 12

By Upflow Flooding Limit - Low Rf 12

Downflow Flooding 13

Intermediate Range 13

Entire Range 13

Conceptual Design 16

Fluid Fill For the Column 16

Dispersed Fluid 17

Tray Layout 20

Flooding Limits 20

Type of Tray 21

Tray Specifications 21

Tray Details - High Velocity Case 21

Tray Details - Low Velocity Case 32

Performance $\quad 34$

Flow rate ratio $\quad 34$

Flow range 34

Fluid Type with Partial Vaporization 34

Single Component Fluid 37

Supercritical Dperation 37

$\begin{array}{ll}\text { Recommendations } & 40\end{array}$

$\begin{array}{ll}\text { References } & 42\end{array}$

Appendix A Modification to the Discrete Region Model 43

Appendix B Analysis of Heat and Mass Transfer For 45 Selecting Hole Diameter and Velocity.

Comparison of Predictions with Experimental Data 45 Discrete Region Model 46 Integrated Region Model 46

Design Conditions for Analysis 50

Optimization 50

Results 52

Conclusions 63 


\section{LIST OF FIGURES}

1. Jetting, drop formation, and drop rise regions

2. Driving forces for conductive heat and mass transfer.

3. Flooding limits versus percent vaporization for liquid/liquid type trays in a geothermal fluid filled column.

4. Flooding observed as carryunder plotted versus worling fluid to geothermal fluid mass flowrate ratio.

5. Working fluid filled, working fluid dispersed sieve tray stages.

6. Fartial boiling, working fluid filled, geothermal fluid dispersed sieve tray stage.

7. Single pass tray - plan view

8. Single pass tray - elevation

9. Double pass tray - plan view

10. Double pass tray - elevation

11. Dimensions and operating conditions for bottom traysingle pass configuration.

12. Design operating conditions and dimensions for liquid/ 1 iquid single pass tray - plan view.

13. Design operating conditions and dimensions for 1 iquid/ 1 iquid single pass tray - elevation.

E-1 Effect of transfer length on dissolved worling fluid

B-2 Effect of high and low velocity on dissolved warting fluid concentration for a 0.13 inch diameter hole.

B-3 Effect of (a) hole velocity and (b) hole diameter on dissolved working fluid concentration predicted by discrete mudel, heat and mass transfer analogy esporient $=.20$

E-4 Effect of (a) hole velocity and (b) hole diameter on dissolved working fluid concentration predicted by discrete model, heat and mass transfer analogy exponent $=.24$

E-5 Effect of (a) hole velocity and (b) hale diameter on dissolved working fluid concentration predicted by discrete model, heat and mass transfer analogy exponent $=.33$

E-6 Dissolved working fluid concentration predicted by the integrated region model for an area factor of 1.0.

B-7 Dissolved worling fluid concentration predicted by the discrete region model for a geothermal fluid 


\begin{abstract}
dispersed column.
B-B Effect of transfer length on dissolved worling fluid concentration for a geothermal fluid dispersed column.

E-9 Effect of mixing (low area factor) and boundary layer thickness on worling fluid concentration shown by concentration versus area factor at various boundary 1 ayer thiclnesses predicted by integrated model.

E-10 Effect of mixing (l ow exponent) on working fluid concentration shown by concentration versus exponent predicted by discrete model.
\end{abstract}




\section{INTRODUCTION}

In prior work, EG\&G subcontract No. K-7752, models for predicting the amount of working fluid dissolved in the geothermal fluid in a direct contact heat exchanger were developed to predict modifications that might achieve these changes. The current work is for the conceptual design of a dicrect contact heat exchanger sieve tray column for the 60 ku HCRF direct contact heat exchanger that would demonstrate or allow for

experimentation leading to reduced working fluid losses due to solution in the geothermal fluid. To do this, the models are modified and extended to match the experimental data and predict the desired range of operating conditions The sxperimental flooding data for mixed partial boiling fluids is reviewed and a model developed to predict this behavior. Then using these models, the column and tray conceptual design is developed. 


\section{SELECTION OF HOLE DIAMETEF AND VELDCITY}

The previous work $k^{1}$ was extended and modified to cover the range of conditions of this project. The most significant modification was the use of a new correlation for drop size developed specifically for these conditions. In addition it was found that it was necessary to develop the concept of upflow flooding described later to 1 imit the transfer achieved at higher rates. The literature correlations for estimating drop size previously reported gave atriormally large drop size. When used the results were grosely in error. Consequently a new correlation was developed based on the data of Meister ${ }^{2}$. This and other modifications to the model are described in Appendiy $A$. These upgraded mathmatical models were then compared with the Faft Fiver experimental data and adjusted so that the predicted and experimental temperature profiles coincided (Appendix $B$ )

The discrete region model calculates the heat and mass transferred for a tray based on the separate estimation of heat and mass transferred in the jetting, the drop formation, and the drop rising region (Figure 1). This model was adjusted by varying an overall scaling factor that in effect adjusted the overall efficiency of the tray so that the predicted temperature profile matched the temperature profile of the experimental data.

The integrated model calculates the heat and mass transfered as the sum of conductive plus convective heat transfered through an interface with some boundary layer thicliness, effective total surface area, and exposure time. The surface area and exposure time is the sum of the values estimated for the individual regions by the correlations of the discrete madel. This model was adjusted so the predited temperature profiles coincided with the experimental data by adjusting the boundary layer thictness and effective area.

These models were then run for given operating conditions to determine the conditions which minimized worling fluid dissolved in the outlet geothermel fluid for the required heat transferred. The results were analysed and operating conditions varied to determine optimum tray configurations for operating conditions of interest. Over 200 cases were run. The conclusions from the results which are described in Appendix $B$ are as follows:

1. The transfer distance, that is the exposure time of a given interface should be minimized. 
Coslesced working fluid layer

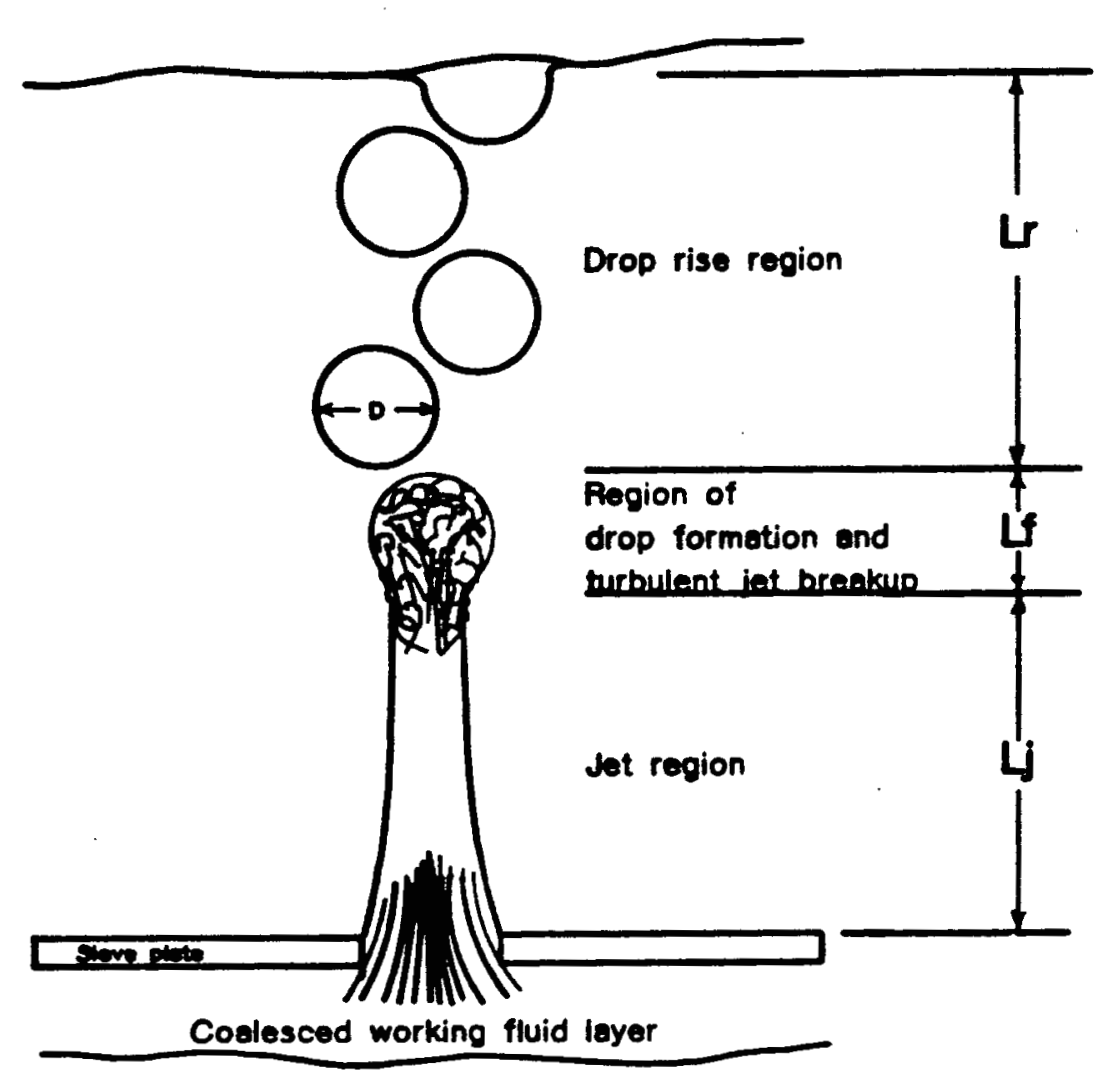

Figure 1. Jetting, drop formation, and
drop rise regions. 
2. The practical optimum hole diameter is 0.25 ".

3. The practical optimum hole velocity can be either a) 1 ow $-0.3 \mathrm{ft} / \mathrm{sec}$. $(10 \mathrm{~cm} / \mathrm{sec}$. $)$ or $1 \mathrm{ess}$, or b) high $-1.2 \mathrm{ft} / \mathrm{sec}$. (40 cm/sec) or greater.

Further conditions discussed later suggest that the more practical velocity is the high velocity case.

These conclusions can be interpreted and explained in terms of the conceptual mechanisms developed by the analysis of the results of the computer runs. 


\section{Mechanistic Interpretation of selection}

The heat and mass transferred in the column is the sum of that transferred in each stage. The amount transferred in each stage is proportional to the driving force, ie., the temperature or concentration difference, and the exposure time. The proportionality constant is the transfer coefficient times the effective area as discussed in the prior work, and is affected by the tray design and $f l$ ow rates. The exposure time is the time the two fluids are in contact, one dispersed in the other, and also is affected by the tray design and flow rates (see Reference 1). This is di discussed later with respect to selecting the tray designi and operating characteristics.

The driving force decreases with time as heat and mass are transferred in any one stage. Since heat is transferred at a more rapid rate, its driving force decreases more rapidly than does the mass transfer driving force. As a consequence the more frequent replacement of fluid at the interface and/or the use of less efficient stages will effect a higher average temperature driving force. The average mass transfer driving force is not significantly affected by such a change since only a small portion is transferred in either case. This is shown in Figure 2 for the case of a jet of fluid issuing from a hole. As a unit of fluid moves from the hole upward heat and mass are transferred by conduction creating the temperatuare and mass concentration profiles shown in Figure 2. Fluid near the surface becomes saturated with respect to temperature during the first interval of time but not with respect to mass because the time scale for equivalent mass saturation concentration is ten times that of heat transfer. The consequence of this is that the rate of heat transfer decreases significantly but the rate of mass transfer does not. This problem of saturation of heat at the interface can be overcome by minimizing the exposure time before the fluid is remixed to form a new interface. This is equivalent to a less efficient tray. The consequence of this is that a lower tray efficiency results in transfer of more heat relative to mass transferred than does a mare efficient tray.

Another way of overcoming this is to create convection within the fluid that replaces the fluid at the interface with cooler fluid. Also, a boundary layer of the proper thickness is advantageous because it decreases the resistance to heat transfer more than for mass transfer (see Reference 1). 

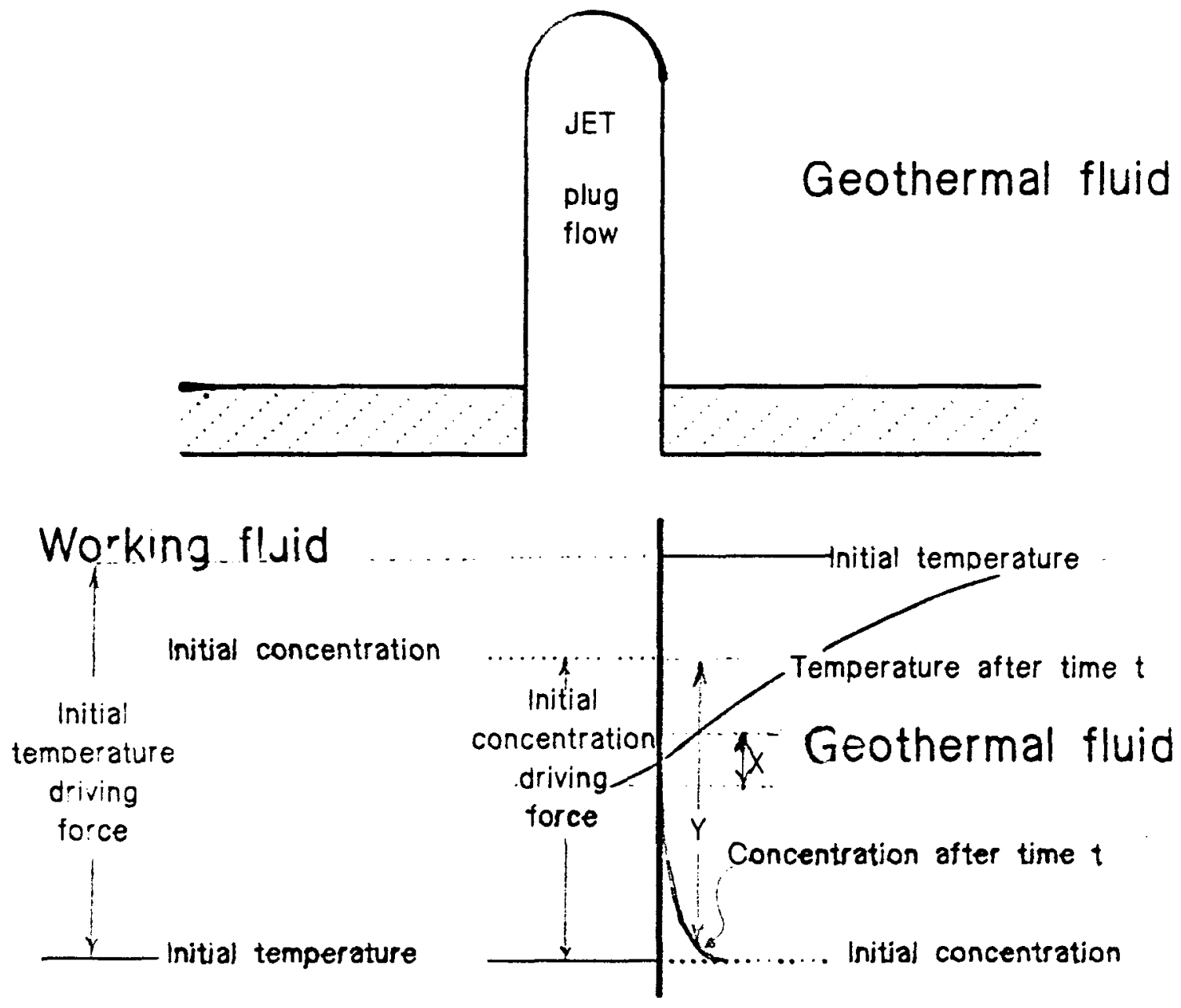

$X$ is temperature oriving force after time $t$

$Y$ is concentration driving force after time $t$

Figure 2. Driving forces for conductive heat and mass transfer. 
The selection of a high velocity above $1.3 \mathrm{ft} / \mathrm{sec}$ or low velocity 1 ess than $0.3 \mathrm{ft} / \mathrm{sec}$ based on the models can be compared with known sieve plate efficiencies for mass transfer. Sieve plate efficiencies are maximum for a kinetic energy factor $F$ between 0.5 and 1.3. The kinetic energy factor $F$ is Ub * $D^{\mu .5}$ where

$$
\begin{aligned}
& \text { Ub = superficial overhead velocity, ft/sec } \\
& \text { D = overhead vapor density, \#/cu.ft. }
\end{aligned}
$$

fbove and below this value the efficiency drops markedly ${ }^{3}$. For the tray design configuration described later with a $1.3 \mathrm{ft} / \mathrm{sec}$ hole velocity, the values of $F$ vary from 1.2 at the tottom of the column to 3 at the boiling section. This coincides with the above consideration which state that above $1.3 \mathrm{ft} / \mathrm{sec}$ the efficiencies are decreased. As discussed this in turn results in a higher heat to mass transferred. The low velocity of $0.3 \mathrm{ft} / \mathrm{sec}$ corresponds to an $F$ factor of 0.3 which is below the value at which efficiency falls dramatically with $F$ with the same consequences as above.

\section{Qther Design Strategies}

Based on the factors in the above discussion and using the same logic, the following additional design strategies can be evolved. A long narrow bubble path across which geothermal fluid flows on the tray should be used to increase the average temperature driving force. In the 1 iquid/liquid portion of the column, a limited transfer. length and either a high velocity with accompanying mixing or a small jet should be used. In the partial boiling region and the boiling region, the low heat capacity vapor should be removed from the transfer zone and the geothermal fluid contacted directly with the higher heat capacity 1 iquid worling fluid. 


\section{FLOODING LIMITATIONS}

The data of Mines et $a^{4}$ was reviewed to determine the conditions which were causing flooding and what these flow limitations were. This data and the associated abservations were interpreted making use of the results of the above analysis together with the hydraulic design methodology for designing geothermal direct contact heat exchanger sieve tray column internals.

\section{Upflow Flooding Limitation.}

Miries et al ${ }^{4}$ found experimentally that the use of trays designed for 1 i quid-liquid transfer for handling mixed fluids which exhibit partial separation worked successfully but at significantly reduced throughput. This is explained by the upflow flooding model and correlating equation developed in this work in extending the prior work for predicting mass and heat transfer in geothermal direct contact heat exchangers.

In a geothermal fluid filled column, the worling fluid flows through the hole forming a jet which breaks into drops. Conceptually, these drops rise in the geothermal fluid at their terminal velocity. When the working fluid flow rate is 1 ow so that there is no interaction between jets or drops, the upflow flooding 1 imit will be given by the terminal velocity of the drops. When the throughput of working fluid reaches a rate such that the drops flowing upward cannot handle it, the column will become chol:ed and the wort:ing fluid will be forced aut the bottom of the column.

In the practical range of flow rates, there is considerable interaction between drops because the volume ratio of working fluid to total volume in the drop rising or bubbling region is 10 to $50 \%$. There will also be interaction between jets, even if only indirectly because of the infuence of neighboring jets on the flow patterns. In such cases, the fluid mixture above the tray will be turbulent (mixed). The ability of the collumn to seperate the two phases in this region will be reduced below that of the terminal velocity. Consequently the velocity flooding limit is given by

$U(f l o o d, b)=C w * U t b$

where 


$$
\begin{aligned}
& U(f l o o d, b)=\text { the terminal velocity of a rising } \\
& \text { drop in the bubbling region } \\
& \text { CW = a coefficient described below. } \\
& \text { Utb = terminal velocity of a drop in the } \\
& \text { bubbling region }
\end{aligned}
$$

In the case of a Iarge volume of working fluid, the geothermal fluid will be carried upward with the working fluid. This is due to entrapment of geothermal fluid in the working fluid as the working fluid flows upward. This flooding mechanism will become important as the ratio fivr of worting fluid to total volume in the drop rising region approaches one. For this limit the coefficient $C w$ will approach zero. As the ratio fivr approaches zero, that is as the rising drops become far apart without interaction, the coefficient will approach one. In extending the analysis of the prior work, it was found that the coefficient should be 0.35 .

For the case of mixed fluids, with partial boiling; the volume of working fluid which must be handled rises dramatically. Consequently at a constant upflow velocity $U(f l o o d, b)$ flooding limit the mass throughput will be greatly reduced. Calculations for the conditions of the experimental column at Faft River using Equation 1 predicts flooding limits which coincide with the experimental results reported by Mines. The comparison shown in Table 1 is interpreted as follows.

Since the fraction vaporization at the various experimental tray locations is not known, this is calculated from Equation 1 using a flooding rate that matches the experimental flooding rate. The calculated values of the fraction vaporization are reasonable and the trend is what would be expected. This flooding would occur at the uppermost tray for partial vaporization. The flooding rates predicted by Equation 1 for the propane and isobutane mixed fluid are platted versus percent vaporization in Figure 3 . Thi shows that the flooding limit falls rapidly with a small fraction of vaporization and then levels. This is compatable with the flooding conditions observed in the Raft fiver mixed fluid runs. Further discussion of the derivation and use of this Equation is given in the next section. 
TABLE 1. COMPARISON OF UPFLOW FLOODING LIMIT PREDICTIONS

Raft River Experimental Data Compared with Equation 1.

\begin{tabular}{|c|c|c|c|c|c|}
\hline \multicolumn{2}{|c|}{ Mixture Composition } & \multirow{2}{*}{$\begin{array}{c}\text { Ratio } \\
R_{f}\end{array}$} & \multirow{2}{*}{$\begin{array}{l}\text { Flooding } \\
\text { Expt'l. } \\
\text { (\#/hr) }\end{array}$} & \multirow{2}{*}{$\begin{array}{l}\text { Rates } \\
\text { Calc'd. } \\
(\# / h r)\end{array}$} & \multirow{2}{*}{$\begin{array}{l}\text { Calc. } \\
\text { Vapor } \\
\text { (wt \%) } \\
\end{array}$} \\
\hline Components & $\%$ Heavy & & & & \\
\hline $\mathrm{C} 4 / \mathrm{C} 6$ & 5 & 1.84 & 9200 & 9200 & 12 \\
\hline $\mathrm{C} 4 / \mathrm{C} 6$ & 10 & 1.98 & 7600 & 7600 & 20 \\
\hline $\mathrm{C} 4 / \mathrm{C} 6$ & 15 & 1.90 & 6580 & 6600 & 24 \\
\hline $\mathrm{C} 3 / \mathrm{C} 5$ & 5 & 1.07 & 4710 & 4700 & 24 \\
\hline $\mathrm{C} 3 / \mathrm{C} 5$ & 10 & 1.19 & 4640 & 4650 & 30 \\
\hline C3/C5 & 15 & 1.29 & 4500 & 4500 & 36 \\
\hline
\end{tabular}

a. This is the weight percent vaporization that gives the calculated flooding rate using Equation 1. 


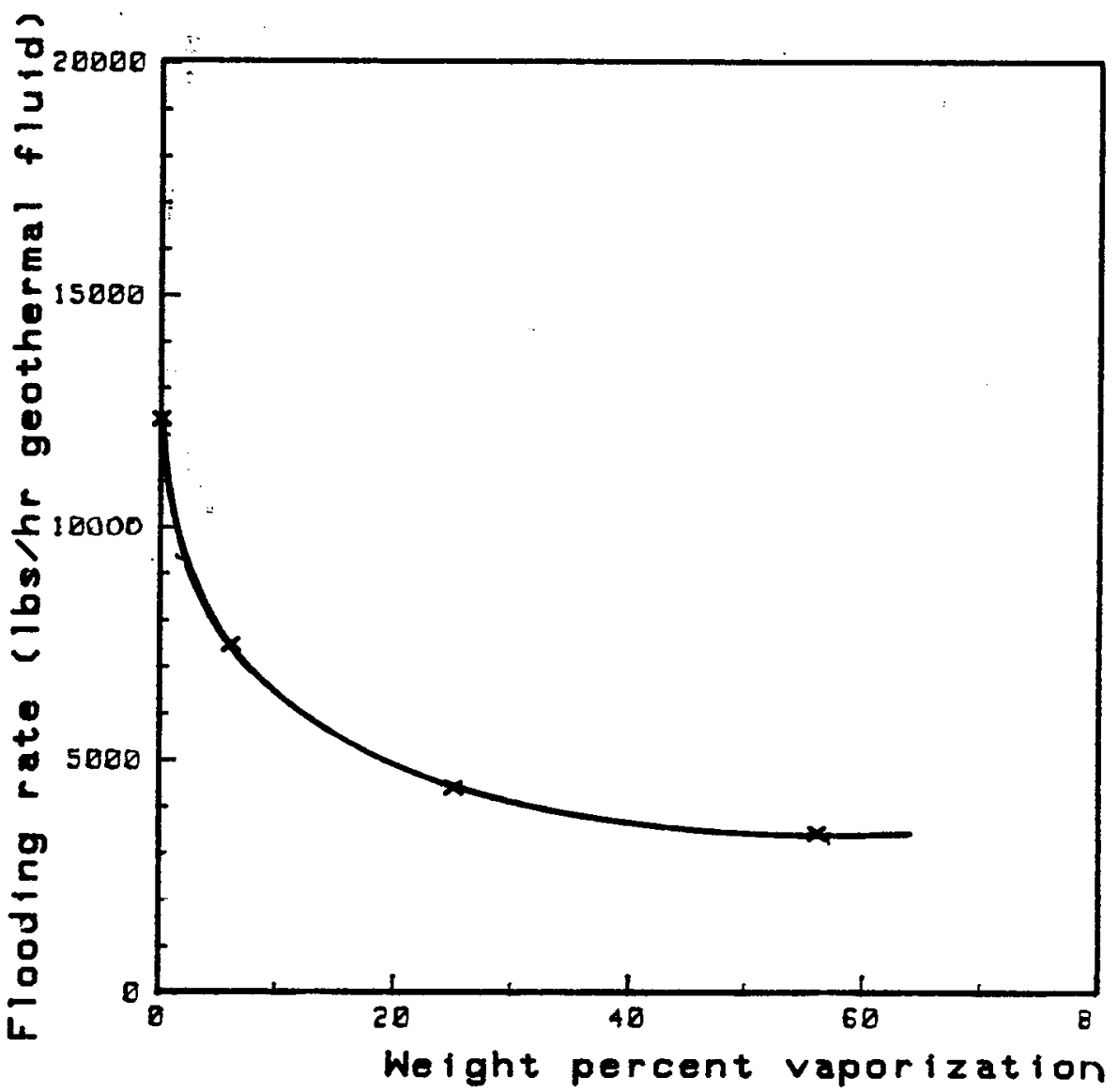

Figure 3. Flooding limits versus percent vaporization for liquid/liquid type trays in a geothermal fluid filled column. 


\section{Downcomer Flooding}

Mines et al state that the underflow gradually increased in dissolved working fluid above $18 \mathrm{gpm}$. They also stated that the column became unstable at a flooding limit usually associated with carryunder of working fluid. They observed as we did also at East Mesa that the geothermal flow rate flooding limit decreases gradually with increasing working fluid flowrate. Since a small change in working fluid hole velocity will not dramatically change the size distribution of dropplets and cause the sudden large amount of carryunder observed, the mechanism of carryunder involving the terminal velocity calculation in the downcomer is not a viable explanation. The mechanism described below explains the observations.

By Upflow flooding limit - High Rf

As the working fluid flow increases, it will reach a rate such that the terminal velocity of the drops is less than the throughput. At this condition, the working fluid flow upward would cease and the column would "choke", that is the working fluid would be forced downward and out with the geothermal fluid. For very dilute bubble concentrations, this would correspond to the upflow flooding limit and would be limited by Utb, the terminal velocity of a drop of working fluid in geothermal fluid. The geothermal fluid mass flow rate Mfd corresponding to this flooding condition is given by

Mfd $=$ Rf * Utb * Ab *D1

where

$$
\begin{aligned}
& \mathrm{Ab}=\text { the bubbling area } \\
& \mathrm{Rf}=\text { mass flow rate ratio, geothermal fluid to } \\
& \text { working fluid. } \\
& \mathrm{D} 1=\text { density of working fluid }
\end{aligned}
$$

Upflow Flooding Limit - Low Rf

However in practice the bubble concentrations are 10 to $30 \%$ of the total volume, which is not dilute. As the concentration of bubbles increase they will coalesce and drag with them the geothermal fluid. 
The geothermal fluid must then find a path to flow back downward, thus decreasing the flooding 1 imit. In practice, however, the fluid mixture will be turbulent (large scale turbulent) and the tray will be mixed. The ability of the fluid to separate before flowing down the downcomer will depend on the separating ability, i.e. the terminal velocity for example, and the volume fraction of working fluid in the mixture. Consequently at high ratios of working fluid to geothermal fluid flow rates, the downcomer flooding which is $1 \mathrm{imited}$ by the separating ability will be determined by the upflow flooding mechanism described above. Thus the geothermal mass flow rate at this flooding limit is given by

Mfd $=\mathrm{Rf} * \mathrm{CW} * \mathrm{Utb} * \mathrm{Ab} * \mathrm{D} 1$

Downflow Flooding

For high geothermal fluid mass flowrates, the flooding 1 imit is reached when the velocity through the downcomer reaches a value sufficient to sweep the working fluid downward. At very low working fluid flow rates this depends on the lower drop size limit, and is conventially taken to be $1 / 16$ to $1 / 32$ inch diameter. In such case the mass flow rate flooding limit is given by

Mfd $=$ Utd * Ad * Dw

where

$$
\begin{aligned}
& \text { Ad }=\text { area of the downcomer } \\
& \text { Utd }=\text { terminal velocity of a "downcomer" drop } \\
& \text { in the geothermal fluid. } \\
& \text { Dw = density of geothermal fluid }
\end{aligned}
$$

\section{Intermedi ate Range}

As the flow rate of working fluid increases, the upflow flooding mechanism combines with the downflow mechanism to decrease the flooding 1 imit below that calculated by Equation 4.

\section{Entire Range}

The result of all this is that the flooding 1 imit is 


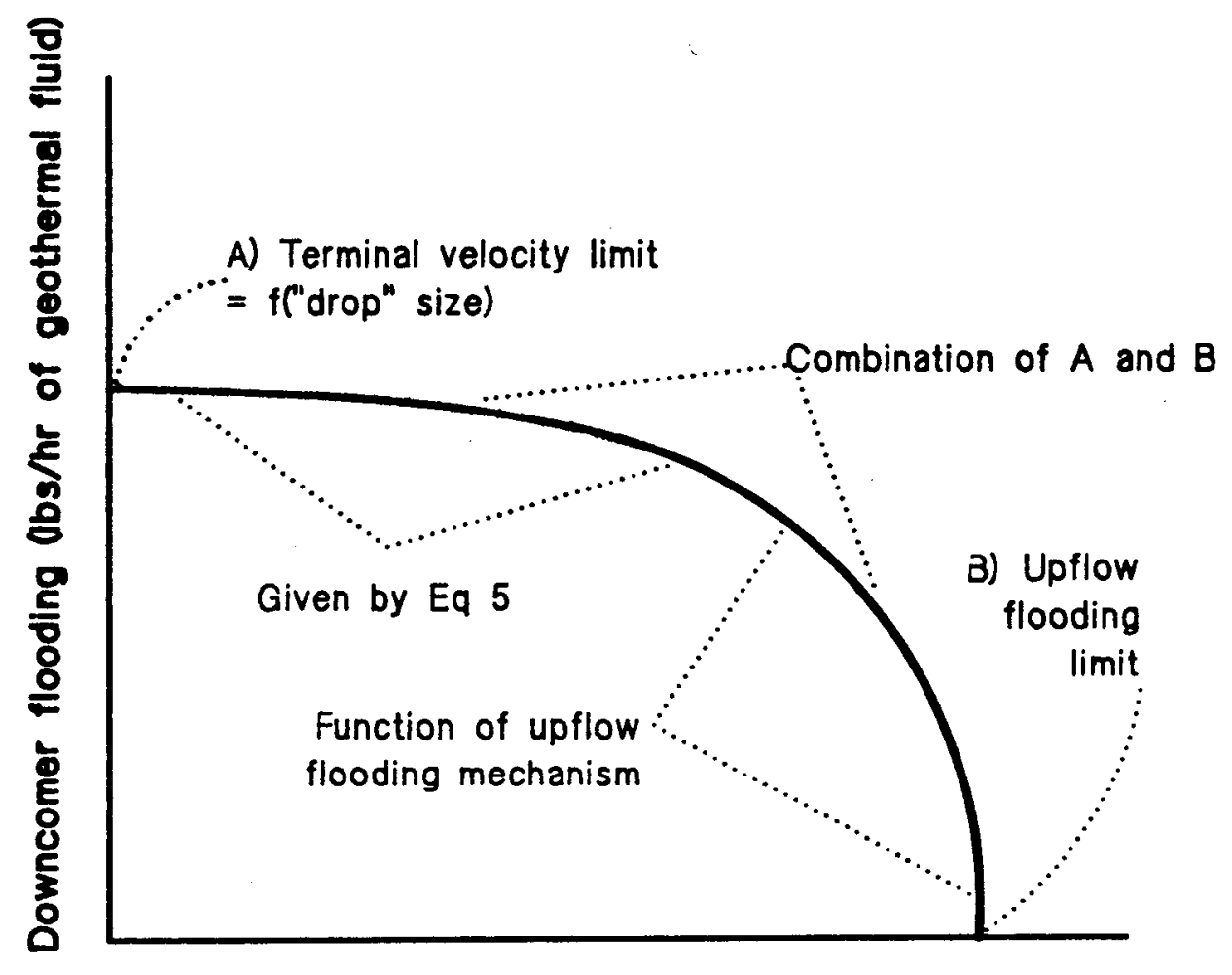

Working fluid to geothermal fluid mass flowrate $=1 / R f$

\footnotetext{
Figure 4. Flooding observed as carryunder plotted versus working.
} 
given by a curve such as shown in Figure 4. How these are combined to correctly predict downcomer flooding in geothermal direct contact heat exchange columns requires further theoretical development. Part of the upper range of downcomer flooding is predicted by a correlation developed for the purpose:

Mfd $=$ Utd $\left[1-0.628\left(1-\operatorname{Rf}{ }^{1.807}\right)\right] * D w * A d$

for Rf $>1.2$.

This correlation is based on East Mesa experimental data (see Reference 5) and was checked against the Raft River data (see Reference 4). 


\section{CONLEFTUAL DESIGN}

To arrive at the conceptual design for an optimum sieve tray for a geothermal direct contact heat exchanger, the column must be designed first. Thus the canceptual design of the tray requires the conceptual design of the entire column, including flow rates arid internals. The data required and the sequence in which it is to be cbtained is as follows:

1. the thermal performance: the temperature and flow rate specifications for the inlet and outlet streams, and the temperature distribution in the column;

2. the optimum hole diameter and hole velocity;

Eoth these items were determined for this case in the section "Selection of Hole Diameter and Velocity."

3. the fluid which is filling the column, or the interface location; and,

4. the selection between working fluid to be dispersed or geothermal fluid to be dispersed.

Hydraulic design and other procedures are then utilized to arrive at tray the layout.

\section{Fluid Fill for the Calumn}

The terminal velocity of $\geq$ drop is proportional to the density of the drop. The ability of a tray to separate the mixed fluids and prevent upflow flooding is directly related to this. Consequently the use of worling fluid to fill the column means the denser geothermal filid will be the drop phase. This is particuiarly important when there is partial boiling, such as with mixed fluids. For example, five weight percent vaporization gives a worling fluid density one-half that of the all-liquid fluid. This would result in an upflow flooding limit of 7000 lbs/hr for a geothermal fluid filled column, rather than the 12,000 lbs/hr plus 1 imit if the fill is worling fluid. See the flooding 1 imit numbers in parens in Table $b$ and the discussion in the section "Tray Layout Flooding Limits".

Consequently a working fluid filled calumn is 
chosen for the design. The interface and level contral is located below the bottom tray. A tray

for a column with dispersed working fluid and a working fluid fill is shown in Figure 5 .

\section{Dispersed Fluid}

Direct contact heat exchangers for geothermal applications have been operated with the working fluid as the dispersed phase. This is therefore the proven method and should be used unless there is an advantage otherwise.

Since mass transfer resistance in the worling fluid phase is zero, it is advantageous to increase the convective mixing and minimize the exposure time of the working fluid phase. A drop of working fluid rising through the geothermal fluid will continually replace the geothermal fluid phase whereas the working fluid phase is trapped within the drop. If however the geothermal fluid is the dispersed phase, then working fluid is continually replaced at the interface increasing the transfer in the warking fluid phase relative to the transfer in the geothermal phase. Consequently the amount of heat transferred relative to the amount of mass transferred is increased. If mixing above the trays is not too severe, then this effect on heat transfer will be significant and there is an advantage to the geothermal fluid being the dispersed phase. Even with mixing, this advantage would probably be significant, but further development of the theoretical madels is necessary to predict the gain that might be achieved by dispersing the geothermal fluid in the working fluid.

Because of the necessity for such further study to predict tray and column behavior, the use of a geothermal fluid dispersed calumn is not further considered in thi $\equiv$ work. The design options are limited to a working fluid dispersed phase which is the system with which there is design and operating experience.

It is worth note however, that there is another advantage to a geothermal dispersed fluid for the case of partial boiling trays, whether mixed fluid or not. For such trays the geothermal fluid drops would pass rapidly through the working fluid vapor during which time no heat transfer is required and then impinge on the working fluid 1 iquid layer as shown in Figure 6. Thereby mass transfer is minimized. 


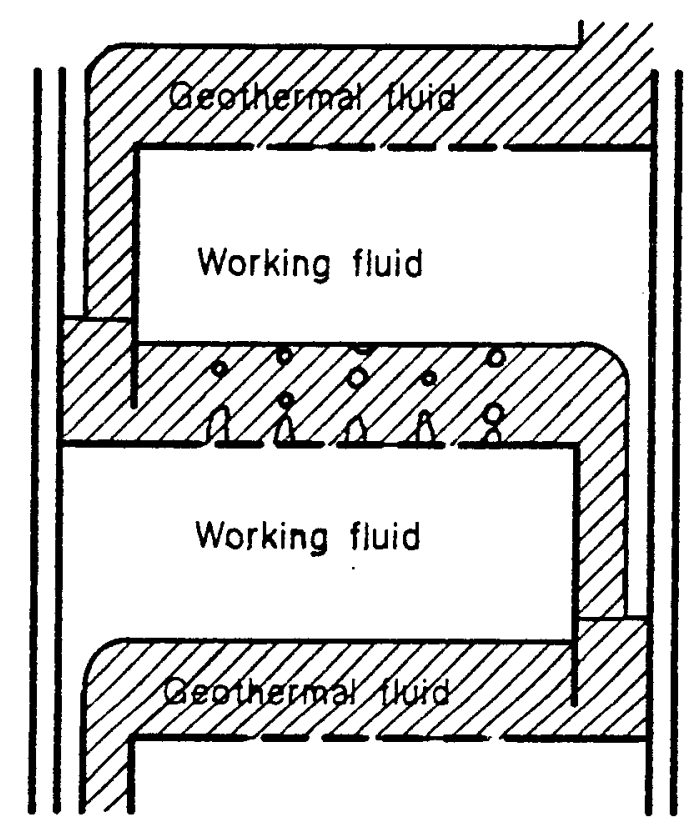

Figure 5. Working fluid filled. working fluid dispersed sieve tray stages. 


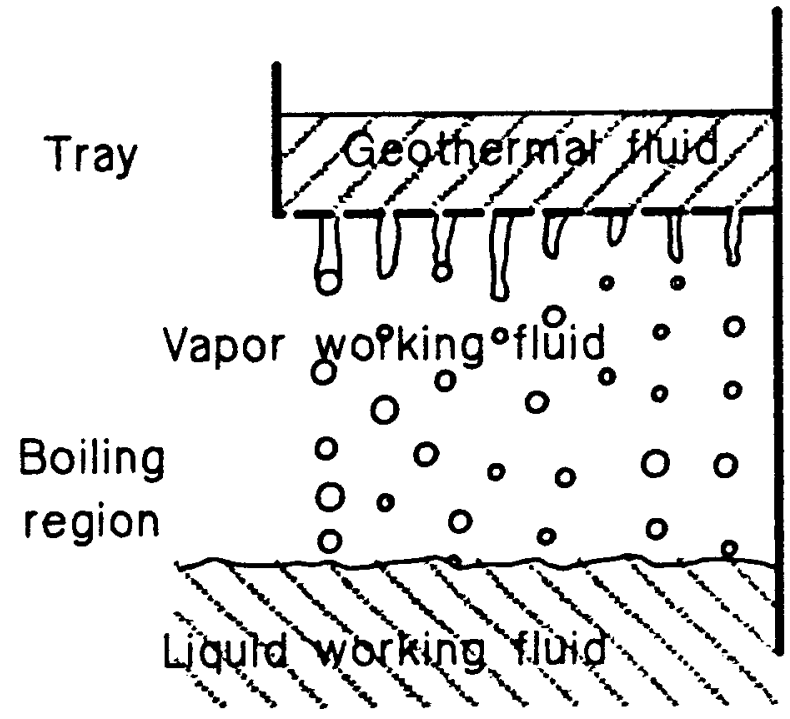

Figure 6. Partial boiling, working fluid filled, geothermal fluid dispersed sieve tray stage. 
Tray Layout

The tray layouts are selected for optimum design for the temperature and fraction vaporization distribution in the column, flow rate ratio, and the specified hole diameter and velocity. The procedure is as follows.

The downcomer area and bubbling region area are balanced so that each region is near its flooding limit. This maximizes mass flow rate. Dne particular tray will probably be limiting the mass flow rate so that other trays may have the same area ratios even though this is not optimum for the other trays.

The other dimensions of the tray are determined so that the appropriate operating characteristics are achieved. These are

- Hw weir height
- Hwt weir overflow level
- Hdt liquid level in the downcomer
- LC head loss across the holes
- Ha apron clearance
- H tray spacing.

The geothermal fluid level on the tray is the weir overflow level. This is adjusted by selecting a small weir height to minimize the transfer length but large enough to have a reasonably small cross flow rate, about 0.5 to $1 \mathrm{ft} / \mathrm{sec}$.

\section{Flooding Limits}

For a working fluid filled colum the flooding rate will be given by the upflow flooding or downcomer flooding mechanisms described above for the 1 iquid/liquid portion of the column. At significant vapor fraction, the correlation for flooding given by Perry (see Reference 2) for vapor disengagement would be expected to apply This flooding velocity $U(f l o o d, g)$ for vapor disengagement is

$U(f 10 o d, g)=C\left[(5 w / .02)^{0.2}\right][(D w-D 1) / D 1 \rho .5$ 
where

$$
\begin{aligned}
& \text { C = coefficient determined graphically(Refrence 2) } \\
& S w=\text { surface tension of geothermal fluid } \\
& \text { Dw = density of geathermal fluid } \\
& \text { D1 = vapor density of overhead working fluid } \\
& U(f l o o d, g)=\text { flooding velocity for vapor disengagement. }
\end{aligned}
$$

\section{Type of Tray}

The crossflow distance should be kept to a minimum in keeping with the principle of maintaining a low tray efficiency and minimizing the exposure time of the geothermal fluid to the working fluid on any given tray. Consquently a double pass tray would be advantageous to a single pass crossflow tray in minimizing dissolved working fluid. These trays are discribed later. The discusion that follows is for a crossflow tray, but applies equally well to a double pass tray. The details of a double pass tray are given, together with any differences from the single pass tray in the discussion.

\section{Tray Specifications}

Conceptual designs are done for both the low (0.4 ft/sec) and high $(1.2 \mathrm{ft} / \mathrm{sec})$ velocity cases. As discussed in the section on "Selecting Hole Diameter and Velocity", the high velocity case is expected to yield better results, but the theory is inadequately developed to predict this. Consequently, conceptual designs are presented for both cases. Since the high velocity case is preferred, it is given in detail whereas only the key features are presented for the low velocity case.

Tray Details - High Velocity Case

The crossflow tray dimensions are shown in Figures 7 and 8 and tabulated in Table 2 . The double pass flow configuration is shown in Figures 9 and 10 . Tray dimensions are the same as in Table 2 . The basic dimensional difference is that the downcomer and bubbling areas are in two halves. 


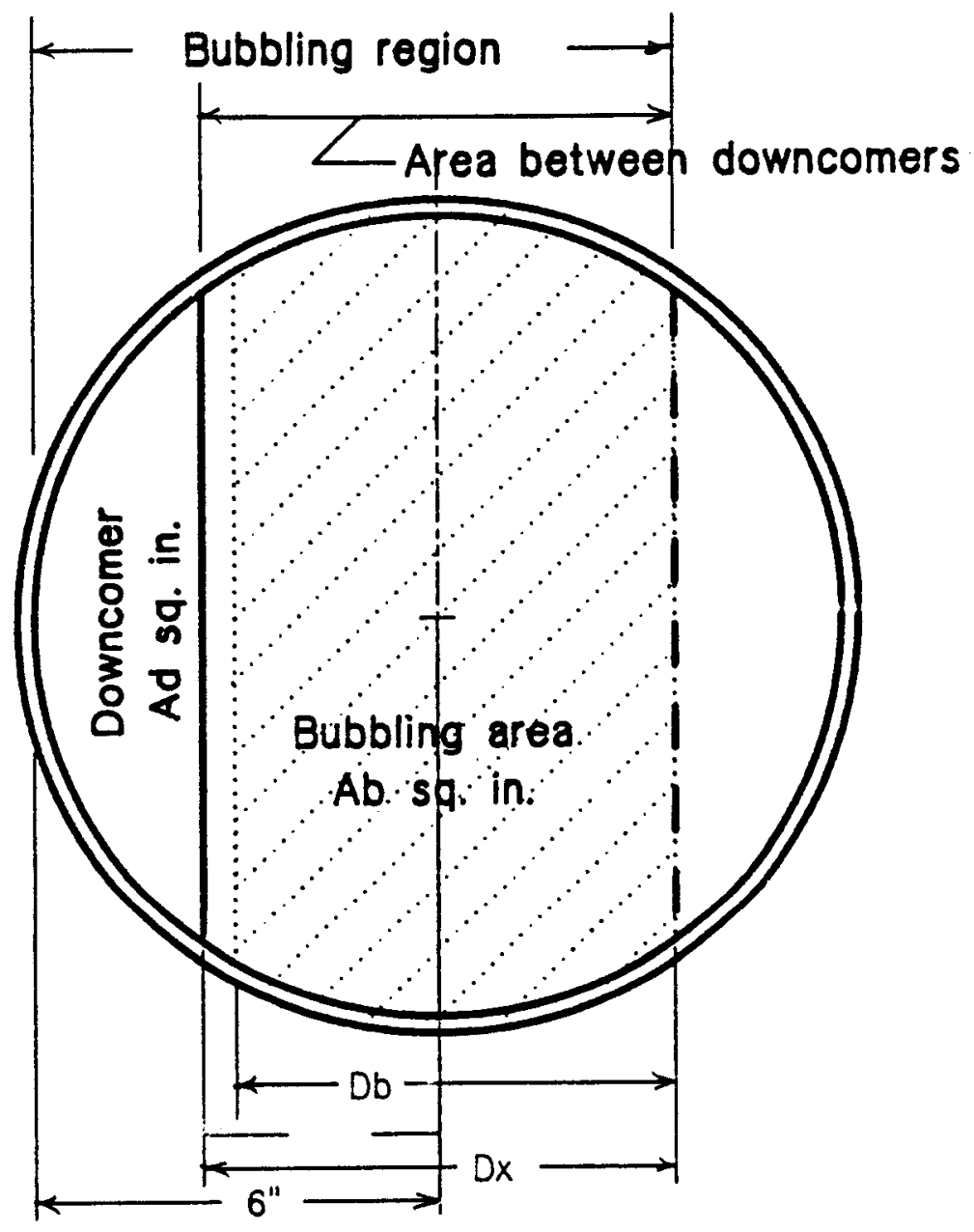

Figure 7. Single pass tray - plan view. 


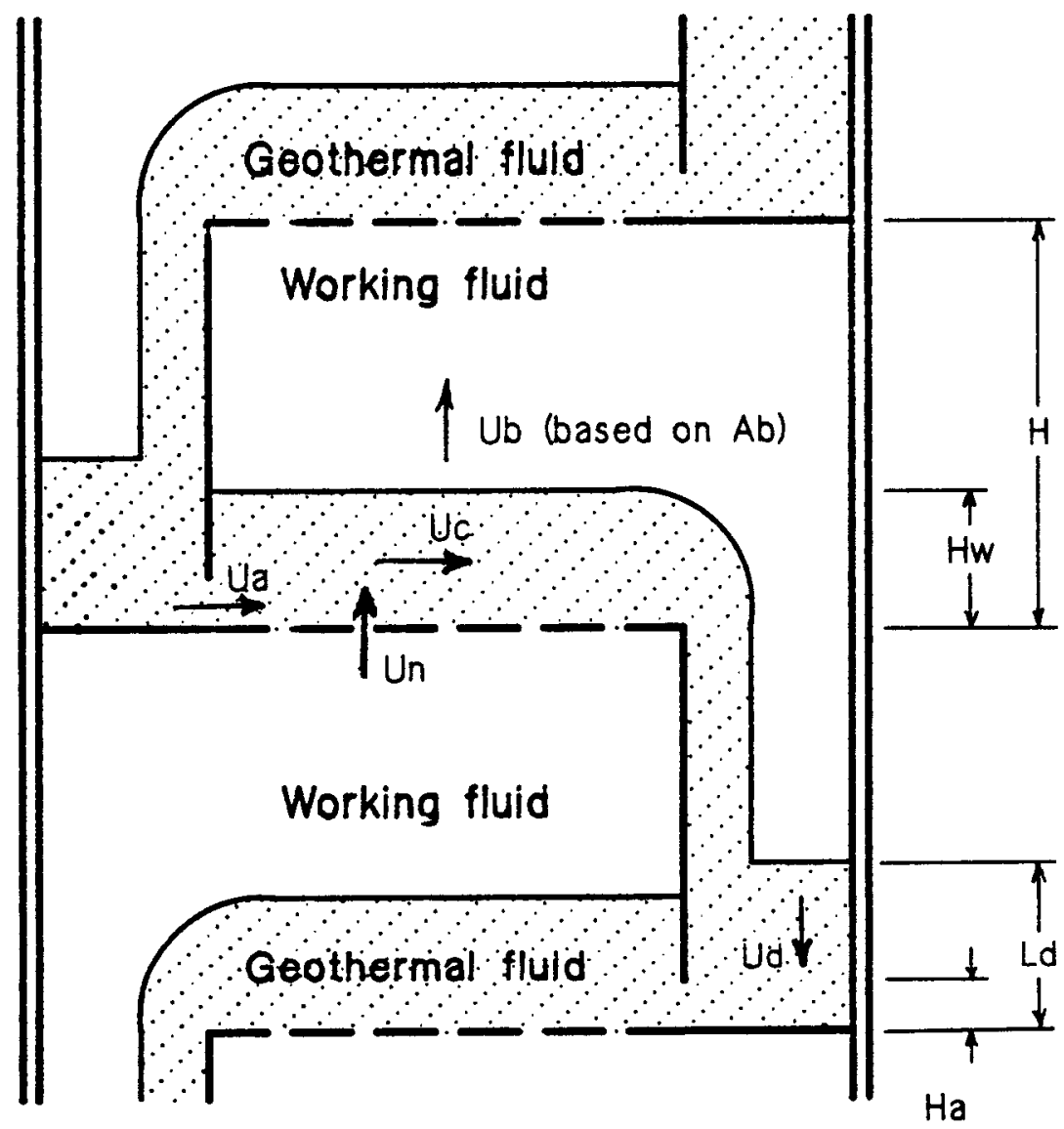

Figure 8. Single pass tray - elevation. 


\section{TABLE 2. TRAY SIZING DATA}

\begin{tabular}{|c|c|c|c|c|c|c|c|c|c|}
\hline $\begin{array}{l}\text { Tray } \\
\text { No. }\end{array}$ & $\begin{array}{l}\text { Hole } \\
\text { size } \\
\text { (in) }\end{array}$ & $\begin{array}{l}\text { Number } \\
\text { of } \\
\text { holes }\end{array}$ & $\begin{array}{l}\text { Open } \\
\text { area } \\
\text { (sq.in.) }\end{array}$ & $\begin{array}{c}\text { Tray } \\
\text { Width Dx } \\
\text { (in.) }\end{array}$ & $\begin{array}{r}X \text { open } \\
\text { area }\end{array}$ & $\begin{array}{c}\text { Bubbling } \\
\text { area } \\
\text { (sq.in.) }\end{array}$ & $\begin{array}{l}9 \text { Tray } \\
\text { above } \\
\text { minimum }\end{array}$ & $\begin{array}{l}\text { Spacing } \\
\text { e Tray (in) } \\
\frac{\text { recom }}{4}\end{array}$ & Service \\
\hline 1 & 0.250 & 374 & 16.9 & 4.6 & 38 & 48.3 & 8 & 16 & Liquid/liquid \\
\hline 2 & 0.250 & 158 & 7.7 & 4.6 & 16 & 48.3 & 8 & 16 & Liquid/liquid \\
\hline 3 & 0.250 & 158 & 7.7 & 4.6 & 16 & 48.3 & 8 & 16 & Liquid/liquid \\
\hline 4 & 0.250 & 197 & 9.7 & 4.6 & 20 & 48.3 & $\theta$ & 18 & $10 \times$ vapor \\
\hline 5 & 0.250 & 276 & 12.1 & 5.2 & 25 & 48.3 & 9 & 18 & $10-75 \times$ vapo \\
\hline 6 & 0.250 & 276 & 121 & 5.2 & 25 & 48.3 & 9 & 18 & $10-75 x$ vapo \\
\hline 7 & 0.250 & 276 & 121 & 5.2 & 25 & 48.3 & 12 & 24 & $100 \times$ vapor \\
\hline 8 & 0.062 & 3970 & 12.1 & 4.6 & 16 & 75.0 & 12 & 24 & $100 x$ vapor \\
\hline
\end{tabular}




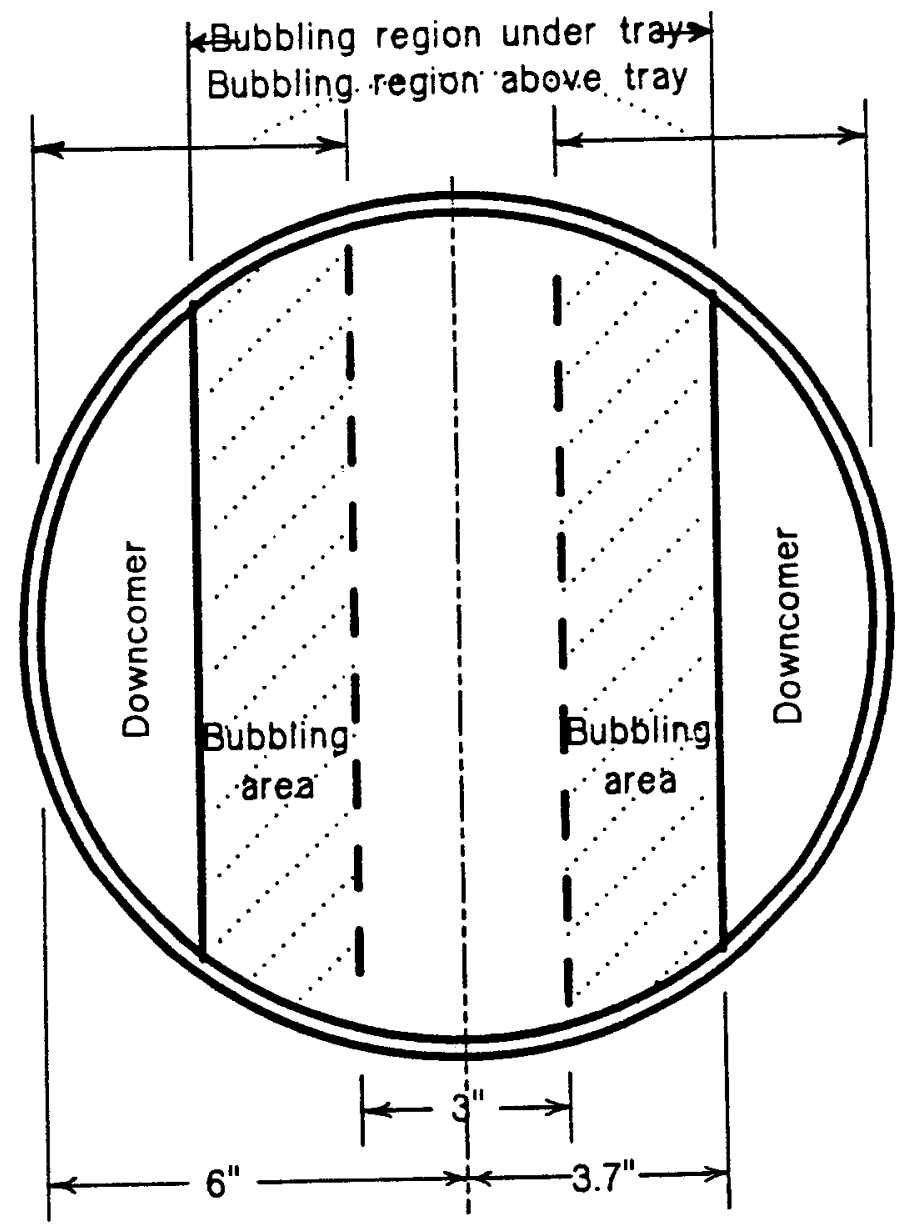

Figure 9. Double pass tray - plan view. 


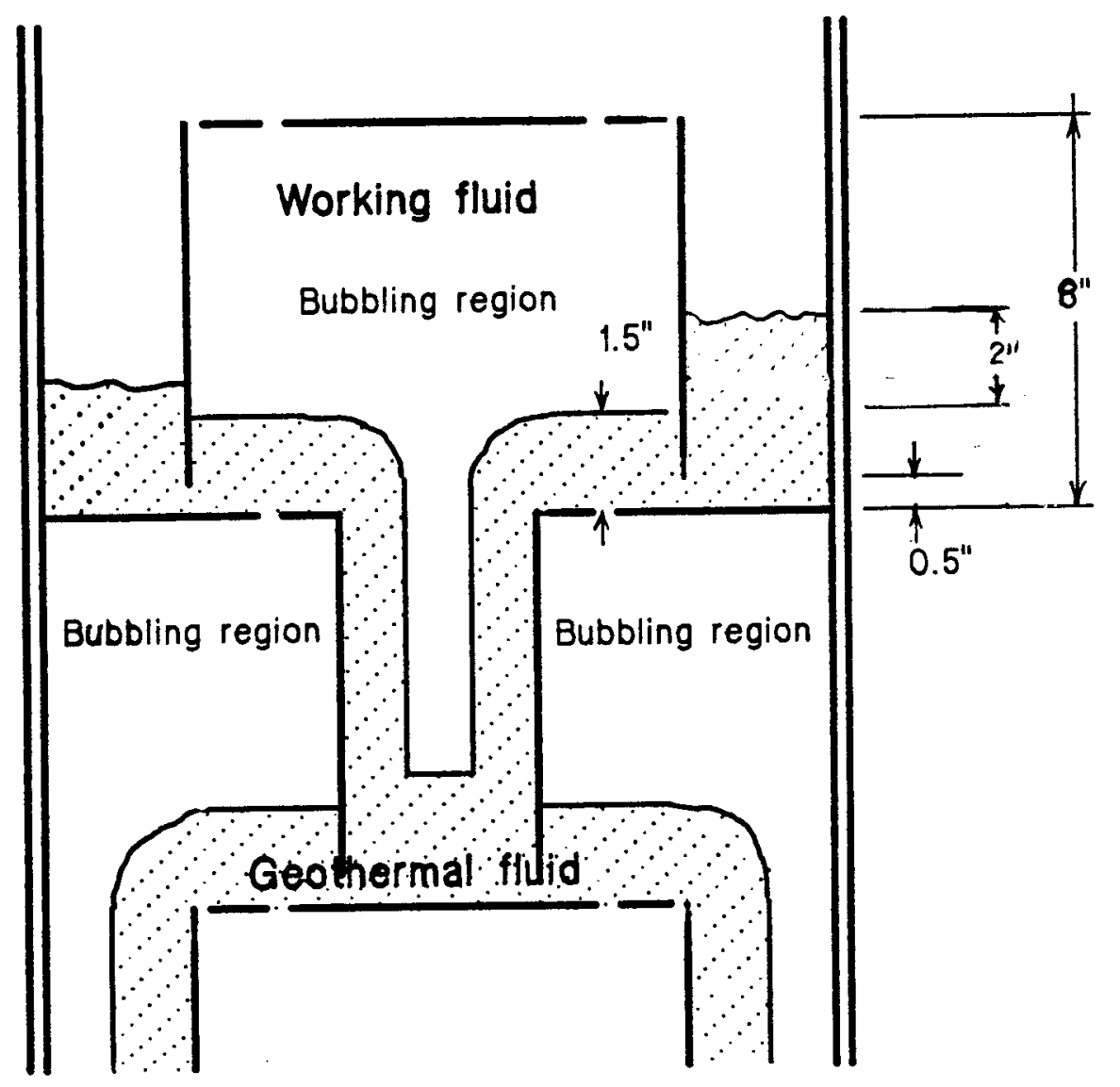

Figure 10. Double pass tray - elevation. 
Bottom Tray. Since mass transfer is not critical in the lower tray, the bottom tray is designed for reducing entrained working fluid rather than minimizing mass transport. This is accomplished by reduing the number of small size drops by decreased hole and apron velocities and consequently decreased energy available for producing smaller size drops. The hole velocity to minimize entrainment is $0.5 \mathrm{ft} / \mathrm{sec}$ through a 0.10 to 0.25 inch hole. The tray design recomended that will achieve this velocity is shown in Figure 11 and the pertinent data given in Table 2. If the column may be run at mass throughputs much less than the design condition, then it may be necessary to reduce the hole size to create sufficient back pressure under the plate to prevent weeping.

Liquid/liquid Trays. The 1 iquid/liquid tray dimensions are those that give the selected velocity of $1.2 \mathrm{ft} / \mathrm{sec}$ or greater and use the desired 0.25 inch hole. Typical values of the 1 iquid levels and velocities are shown in Figure 12 and 13 for the design flow rate of $12,0001 \mathrm{bs} / \mathrm{hr}$ of geothermal fluid and a flow rate ratio of 1.4 .

Partially vaporized trays. These trays use the desired 0.25 inch diameter holes, but the number of holes is increased to maintain a reasonable hole velocity. Hole velocities for typical fraction vaporization through this section for design flow rates is shown in Table 3 . Also, the bubbling area is increased by increasing tray bubbling width Dx from 4.6 to 5.2 inches. This decreases the downcomer area and reduces throughput capacity for the single component all liquid column from 13,000 $1 \mathrm{bs} / \mathrm{hr}$ to 12, OOO 1bs/hr.

Boiling trays. For a single component working fluid boiling at constant temperature, all vaporization will take place on one or two trays. Special consideration needs to be given to this because of the large change in volume ratio between the inlet and outlet working fluid streams for the tray. If all boiling takes place on the upper tray, then the only consideration is that the geothermal fluid be properly distributed on this tray and that a reservair is provided for geothermal fluid so that the liquid working fluid on entering the tray makes adequate contact with the geothermal 


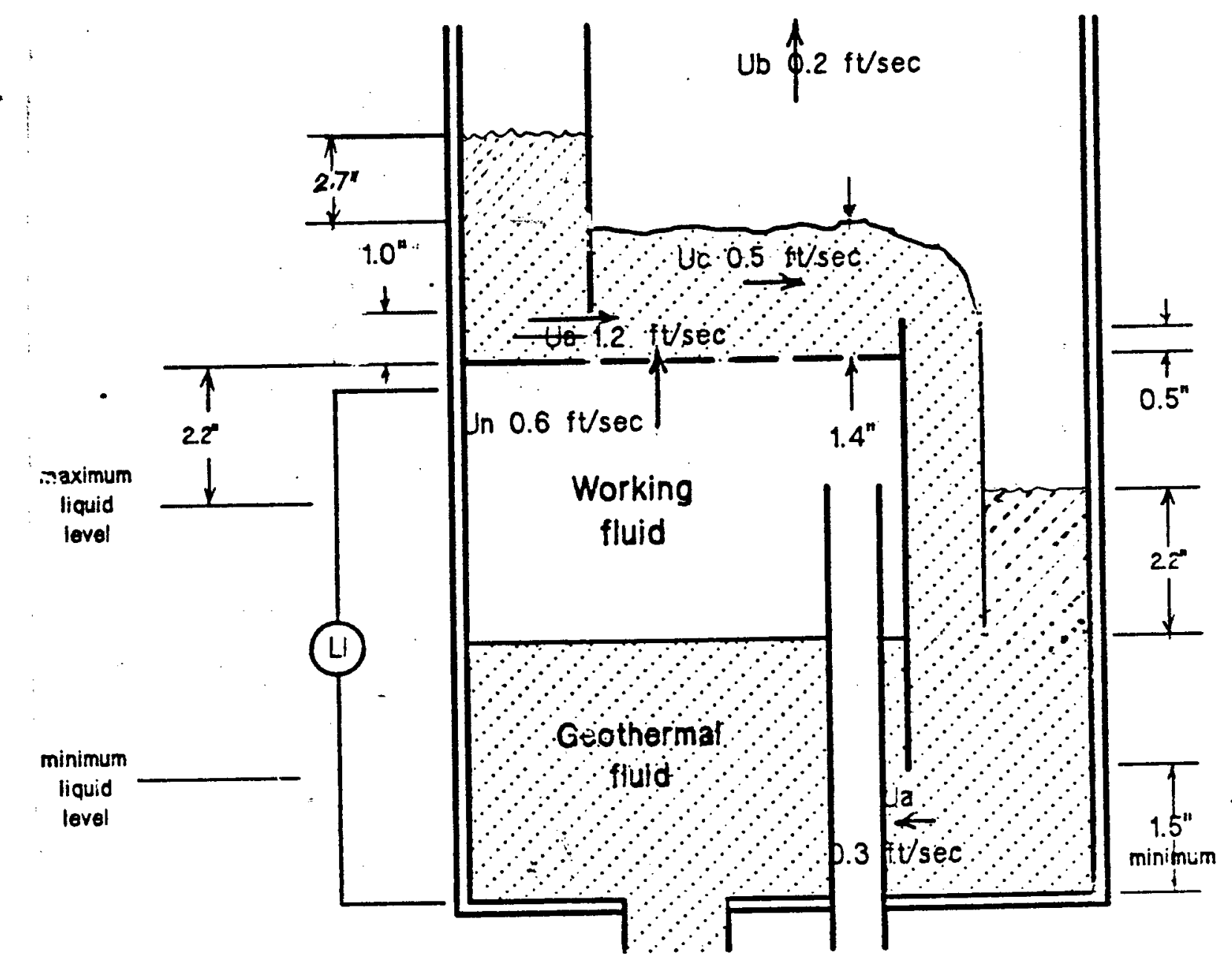

Figure 11. Dimensions and operating conditions for bottom tray - single pass configuration. 


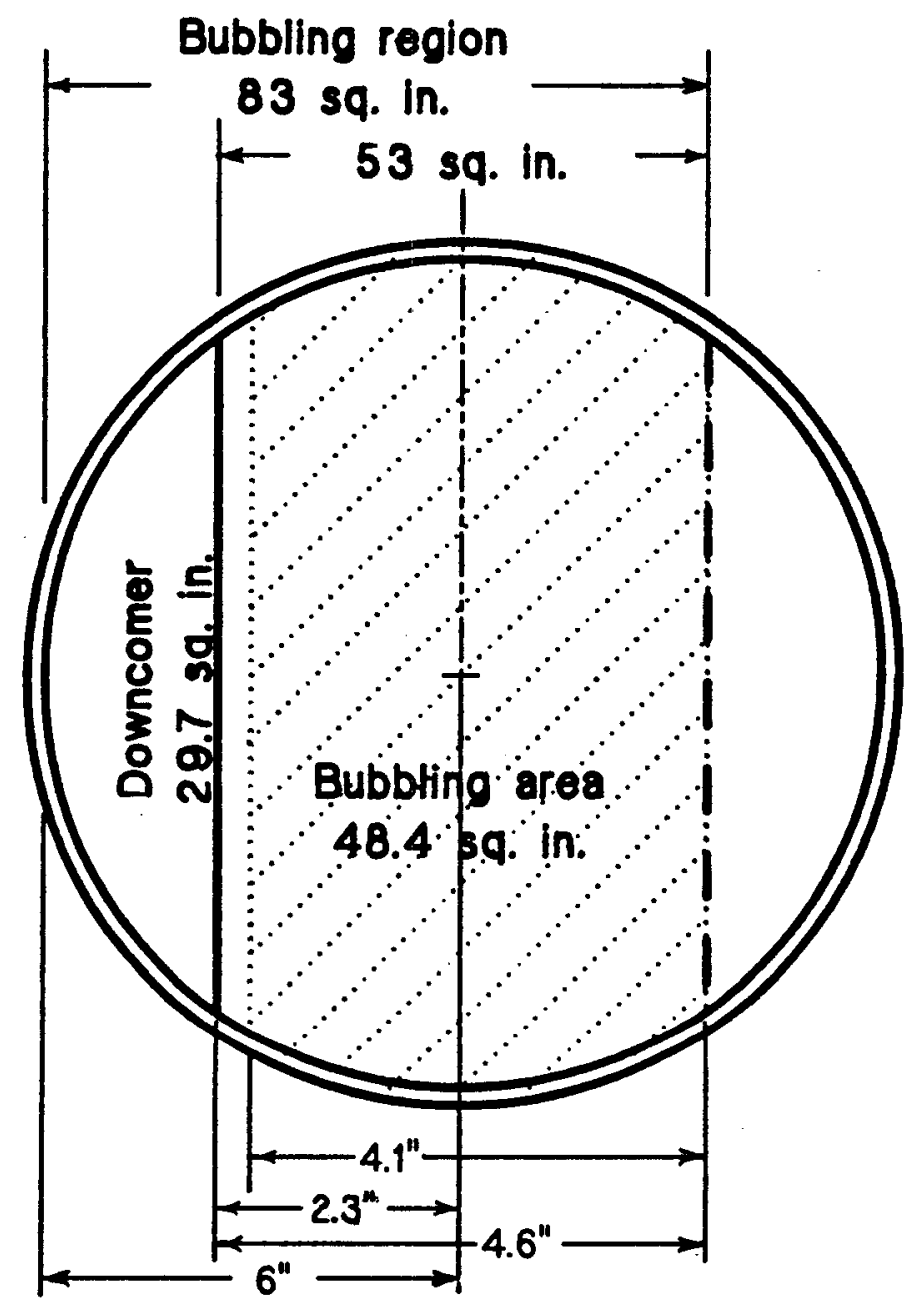

Figure 12. Design operating conditions and dimensions for liquid/liquid single pass tray-plan view. 


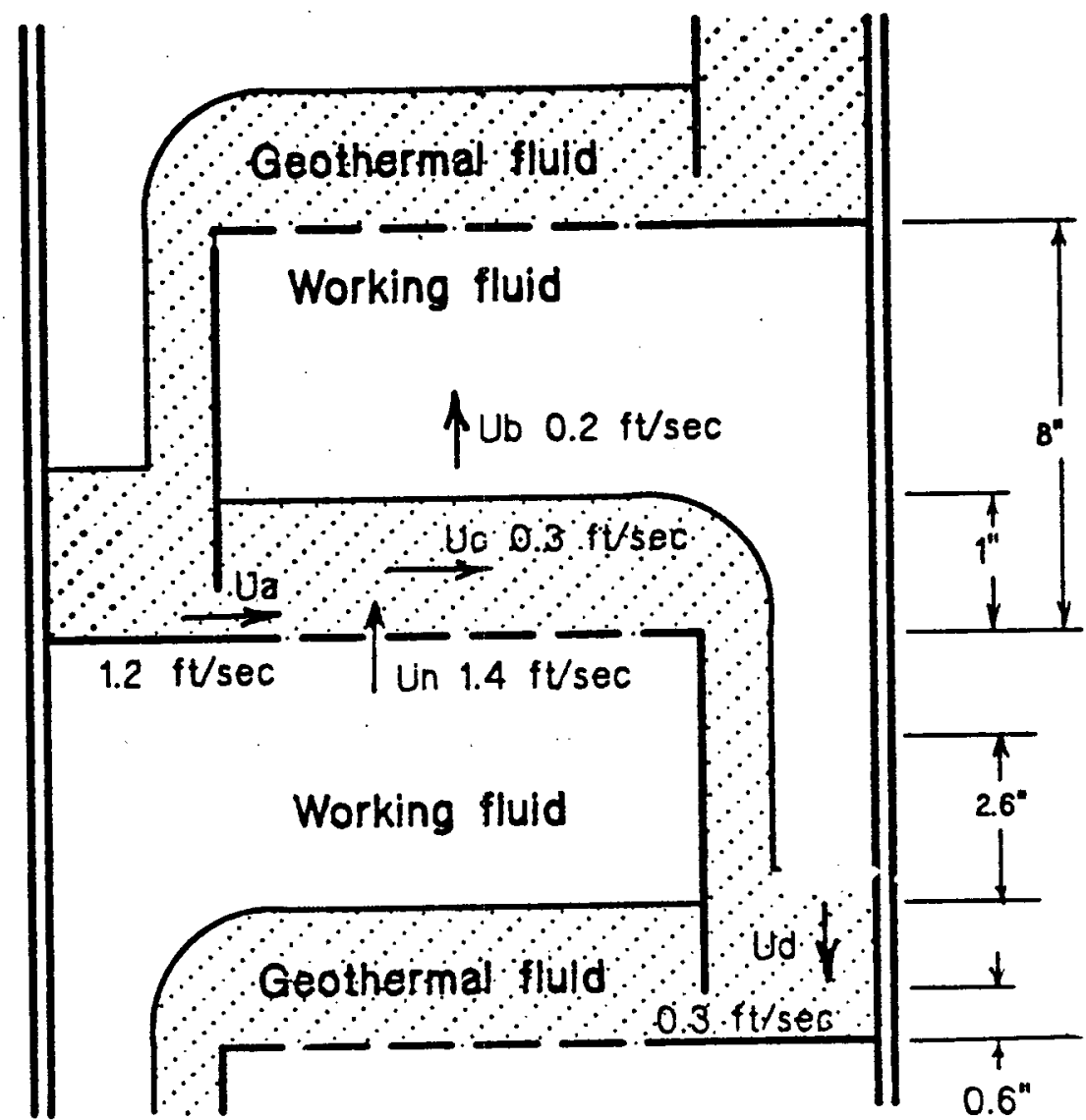

Figure 13. Design operating conditions and dimensions for liquid/liquid single pass tray - elevation. 
TABLE 3. HOLE VELOCITIES FOR DESIGN CONDITIONS

\begin{tabular}{|c|c|c|c|}
\hline $\begin{array}{l}\text { Tray } \\
\text { No. }\end{array}$ & $\begin{array}{l}\text { Hole area } \\
\text { (sq. in.) }\end{array}$ & $\begin{array}{l}\text { Vaporization } \\
\text { (weight \%) }\end{array}$ & $\begin{array}{l}\text { Hole velocity } \\
(\mathrm{ft} / \mathrm{sec})\end{array}$ \\
\hline 1 & 18.4 & 0 & 0.6 \\
\hline 2 & 7.7 & 0 & 1.4 \\
\hline 3 & 7.7 & 0 & 1.4 \\
\hline 4 & 9.7 & 6 & 2.3 \\
\hline 5 & 13.6 & 25 & 3.0 \\
\hline 7 & 13.6 & 56 & 3.9 \\
\hline 8 & 15.1 & 100 & 4.4 \\
\hline
\end{tabular}


fluid. If boiling takes place on the second tray from the top, then provision must be made for adequately separating the boiling mixture. This means that the tray spacing should be increased to allow for this. The preferred mode of operation is for all boiling to take place on the upper tray.

Top tray. Because of the phase change that is occuring on the top plate, a large surface area and small diameter jets will promote faster conversion of 1 iquid to vapor. This will minimize mass transferred. Consequently the top tray uses $0.062(1 / 16)$ inch diameter holes. Provision must be made for properly distributing the inlet geothermal fluid over this tray.

Tray Details- Low Velocity case.

The dimensions required to acheive the desired 0.3 $\mathrm{ft} / \mathrm{sec}$. hole velocity in the $\mathrm{liquid/liquid}$ section are shown in Table 4a. The hole velocities that result for a flow rate of 8,000 lbs./hr. are given in Table 4b. At this flow rate al1 levels and pressure drops for all trays are reasonable and give proper performance. This reduced flow rate is necessary to acheive the required hole velocity in the available area, with the same downcomer area as for the 12,000 1b./hr. high velocity tray described above. 
TABLE 4a. SIZING DATA FOR LOW VELOCITY TRAY

\begin{tabular}{|c|c|c|c|c|c|c|c|}
\hline $\begin{array}{l}\text { Tray } \\
\text { No. }\end{array}$ & $\begin{array}{l}\text { Hole } \\
\text { size } \\
\text { (in) }\end{array}$ & $\begin{array}{c}\text { Number } \\
\text { of } \\
\text { holes }\end{array}$ & $\begin{array}{c}\text { Open } \\
\text { area } \\
\text { (sq.in.) }\end{array}$ & $\begin{array}{c}\% \text { open } \\
\text { area }\end{array}$ & $\begin{array}{c}\text { Bubbling } \\
\text { area } \\
\text { (sq.in.) }\end{array}$ & $\begin{array}{l}\text { Tray } \\
\text { spacing } \\
\text { (in) }\end{array}$ & Service \\
\hline 1 & 0.125 & 1773 & 21.8 & 45 & 48.3 & 6 & Liquid/liquid \\
\hline 2 & 0.125 & 1773 & 21.8 & 45 & 48.3 & 6 & Liquid/liquid \\
\hline 3 & 0.125 & 1773 & 21.8 & 45 & 48.3 & 6 & Liquid/liquid \\
\hline 4 & 0.250 & 443 & 21.8 & 45 & 48.3 & 6 & $10 \%$ vapor \\
\hline 5 & 0.250 & 443 & 21.8 & 45 & 48.3 & 9 & $10-75 \%$ vapor \\
\hline 6 & 0.250 & 443 & 21.8 & 45 & 48.3 & 9 & $10-75 \%$ vapo \\
\hline 7 & 0.250 & 443 & 21.8 & 45 & 48.3 & 12 & $100 \%$ vapor \\
\hline 8 & 0.062 & 7206 & 21.8 & 45 & 75.0 & 12 & $100 \%$ vapor \\
\hline
\end{tabular}

TABLE 4B. HOLE VELOCITIES FOR DESIGN CONDITIONS LOW VELOCITY TRAY.

\begin{tabular}{ccc}
$\begin{array}{c}\text { Tray } \\
\text { No. }\end{array}$ & $\begin{array}{r}\text { Vaporization } \\
(\text { weight } \%)\end{array}$ & $\begin{array}{r}\text { Hole velocity } \\
(\mathrm{ft} / \mathrm{sec})\end{array}$ \\
\cline { 2 - 3 } 1 & 0 & 0.3 \\
2 & 0 & 0.3 \\
3 & 0 & 0.3 \\
4 & 6 & 0.7 \\
5 & 25 & 1.2 \\
7 & 56 & 1.6 \\
8 & 100 & 1.0
\end{tabular}




\section{PERFORMANCE}

Calculations were run on the high velocity tray design specified above for a variety of operating conditions to determine the performance of the design. All items listed above in addition to others were calculated and checked to be certain that the column would perform properly for the following conditions:

- hole velocities from 0.1 to $2 \mathrm{ft} / \mathrm{sec}$

- geothermal to working fluid mass flow rate ratios from 100\% propane to $100 \%$ pentane

- Mixed fluids with partial vaporization

- Sirigle comporent fluid with boiling

- supercritical isobutane.

\section{Flow Fiate Fiatio}

The geothermal fluid flacding limit mass flowrate varies from 13,000 lbs/hr to 9,800 lbs/hr as the geothermal to working fluid mass flow rate ratio decreases from 1.6 to 1.2. This is shown in Table 5 together with 1 i quid level ranges and the hole pressure lasses. These values are all acceptable for good operation.

\section{Flow Fiange}

The mayimum flow rate is limited by flooding and as shown in Tables 5 and 6 is general1y 12,000 to 13,000 lbs/hr except at high worling fluid to geothermal fluid flow rate ratios. The minimum geothermal fluid flow rate is that required to seal the apron clearance, and is 7,000 1bs. /hr.

\section{Fluid Type with Fartial Vaporization}

The performance of the column with a variety of mixed fluids ranging in average properties from that of propane to pentane for partial vaporization is shown in Table 6. the flooding 1 imit flow rate of geothermal fluid varies from 11,800 to $12,800 \mathrm{lbs} / \mathrm{hr}$. 
TABLE 5. DESIGN LIMITS AND LEVELS FOR VARIOUS GEOTHERMAL FLUID TO WORKING FLUID FLOW RATE RATIOS, $\mathrm{R}_{f}^{f}$.

\begin{tabular}{|c|c|c|c|c|c|}
\hline \multirow{3}{*}{$\begin{array}{l}\text { Ratio } \\
\mathrm{R}_{\mathrm{f}-}\end{array}$} & \multirow{2}{*}{\multicolumn{2}{|c|}{ Geo Flow (lb/hr) }} & \multirow{3}{*}{$\begin{array}{l}\text { Levels (in) at } \\
\text { Downcomer, Ld }\end{array}$} & \multirow{2}{*}{$t$ design } & \multirow{3}{*}{$\begin{array}{l}\text { Hole } \\
\text { Pres Loss } \\
\text { Head (in) } \\
\end{array}$} \\
\hline & & & & & \\
\hline & $\underline{\text { Limit }}$ & Design & & Weir, Hw & \\
\hline 1.2 & $10,: 00$ & 9,800 & 1.8 to 2.1 & 1.0 & 0.5 to 0.8 \\
\hline 1.4 & 12,800 & 12,000 & 2.2 to 2.5 & 1.0 & 0.5 to 0.9 \\
\hline 1.6 & $1+00$ & 13,000 & 2.3 to 2.6 & 1.0 & 0.5 to 0.8 \\
\hline
\end{tabular}

a. above geothermal liquid weir level $\mathrm{Hw}$ on tray

b. tray 1 is 0.1 in head loss, 1.5 in. weir height $\mathrm{Hw}$ 
TABLE 6. LOWEST FLOODING RATES (Ibs/hr) BY REGION FOR THE COLUMN AS DESIGNED USING ISOBUTANE

\begin{tabular}{|c|c|c|c|c|c|c|c|c|}
\hline \multirow[b]{2}{*}{ Fluid } & \multicolumn{4}{|c|}{---- Bubbling (overhead)----- } & \multirow[b]{2}{*}{$\begin{array}{c}\text { Dwncmr } \\
\text { o\%vapr }\end{array}$} & \multicolumn{3}{|c|}{ Column Limiting } \\
\hline & $\begin{array}{l}\text { Liquid } \\
\text { 0\%vapor }\end{array}$ & $\begin{array}{l}\text { Partial } \\
50 \text { vol } \%\end{array}$ & $\begin{array}{l}\text { vapor }{ }^{\prime} \text { tn } \\
\text { vapor }\end{array}$ & $\begin{array}{c}\text { Vapor } \\
100 \%\end{array}$ & & Regn & Tray & y Rate \\
\hline & ---- & Minimum & tray spac & ing---- & & & & \\
\hline $\begin{array}{c}c 3 \\
i-c 4 \\
c 5\end{array}$ & $\begin{array}{l}17,700 \\
17,000 \\
17,300\end{array}$ & $\begin{array}{l}15,000 \\
15,400 \\
12,600\end{array}$ & $\begin{array}{l}(9150) \\
(9150) \\
(8240)\end{array}$ & $\begin{array}{r}12,800 \\
12,300 \\
8,600\end{array}$ & $\begin{array}{l}13,900 \\
13,000 \\
12,000\end{array}$ & $\begin{array}{l}\text { vapor } \\
\text { rapor } \\
\text { vapor }\end{array}$ & {$\left[\begin{array}{l}8 \\
8 \\
8\end{array}\right.$} & $\begin{array}{r}12,800 \\
12,300 \\
8,600\end{array}$ \\
\hline & --Two & times min & limum tray & i & & & & \\
\hline $\begin{array}{c}c 3 \\
i-c 4 \\
c 5\end{array}$ & $\begin{array}{l}17,700 \\
17,000 \\
17,300\end{array}$ & $\begin{array}{l}15,000 \\
15,400 \\
12,600\end{array}$ & $\begin{array}{l}(13000) \\
(13300) \\
(12200)\end{array}$ & $\begin{array}{l}20,300 \\
13,000 \\
13,900\end{array}$ & $\begin{array}{l}13,900 \\
19,400 \\
12,000\end{array}$ & $\begin{array}{l}\text { dwncmr } \\
\text { dwncmr } \\
\text { dwncmr }\end{array}$ & $\begin{array}{ll}1 & 1 \\
1 & 1 \\
1 & 1\end{array}$ & $\begin{array}{l}13,900 \\
13,000 \\
12,000\end{array}$ \\
\hline
\end{tabular}

a. The number in parenthesis is the flooding limit if the flooding mechanism corresponding to Perry's correlation Equation 6 were to apply. 


\section{Single Component Fluid}

A single component fluid will boil on the top tray and the remainder of the trays will be all 1 iquid. Since trays 4 through 6 are designed for partial vaporization, the hole velocities (Table 7) for all liquid operation will be 1 ess than the desired $1.3 \mathrm{ft} / \mathrm{sec}$. Consequently a modified design as shown in Table 8 would provide higher velocities for this case, but at the expense of higher velocities than desired for the design operating conditions, also shown in Table B. Also because trays 5-7 have smaller downcomers, the downcomer flooding 1 imit is reduced from $13,0001 \mathrm{bs} / \mathrm{hr}$ to 12,000 lbs/hr for isobutane operating as all liquid through tray 7.

\section{Supercritical Operation}

Dperation with supercritical isobutane poses no special problems. The hole velocities and 1 i quid heights are shown for this case in Table 8 . This table shows that the comment regarding hole velocities for the single component fluid applies to this case also. 
TABLE 7 HOLE VELOCITIES FOR ISOBUTANE BOILING ON TOP TRAY ONLY

\begin{tabular}{r} 
Tray \\
No. \\
\hline 1 \\
1 \\
2 \\
3 \\
4 \\
5 \\
6 \\
7 \\
8
\end{tabular}

\begin{tabular}{c} 
Hole Velocity \\
ft/sec \\
\hline 0.6 \\
1.4 \\
1.5 \\
1.5 \\
1.2 \\
1.1 \\
1.1 \\
4.4
\end{tabular}



$\begin{array}{ll}\text { TABLE } 8 & \text { HOLE VELOCITIES ( } \mathrm{t} / \mathrm{sec} \text { ) OF STANDARD AND MODIFIED } \\ & \text { TRAY DESIGN FOR DESIGN, ALL LIQUID, AND SUPERCRITICAL } \\ & \text { OPERATING CONDITIONS }\end{array}$

\begin{tabular}{|c|c|c|c|c|c|c|c|c|}
\hline \multirow{3}{*}{$\begin{array}{l}\text { Tray } \\
\text { No }\end{array}$} & \multirow{3}{*}{$\begin{array}{l}\text { Open } \\
\text { area }\end{array}$} & \multicolumn{3}{|c|}{ Standard Design } & \multicolumn{4}{|c|}{ Modified Design } \\
\hline & & & $\overline{A 11}$ & & Open & & A11 & \\
\hline & & Design & lig & Supercrit & Area & Design & $\underline{1 i q}$ & Supercrit \\
\hline 1 & 16.9 & 0.6 & 0.6 & 0.6 & 16.9 & 0.6 & 0.6 & 0.6 \\
\hline 3 & 7.7 & 1.4 & 1.4 & 1.3 & 7.7 & 1.4 & 1.4 & 1.4 \\
\hline 4 & 7.7 & 2.9 & 1.5 & 1.4 & 7.7 & 2.9 & 1.5 & 1.5 \\
\hline 5 & 9.7 & 4.2 & 1.2 & 1.2 & 8.7 & 4.7 & 1.4 & 1.4 \\
\hline 7 & 12.1 & 4.4 & 1.1 & 1.1 & 9.7 & 5.5 & 1.3 & 1.3 \\
\hline 8 & 12.1 & 4.4 & 4.4 & 4.4 & 12.1 & 4.4 & 4.4 & 4.4 \\
\hline
\end{tabular}


RECOMMENDATIONS

Column and Tray Modifications

The recommended design is a working fluid filled, working fluid dispersed column with eight trays. All of the recommended tray design information is contained on Wahl Company drawings 84144001 for the single pass tray and 84144003 for the double pass tray. The double pass tray is preferred over the single pass tray, but the gain may not be significant. This information is also given in the text for either single pass in Figures 7 and 8 or double pass in Figures 8 and 9 with dimensions as shown in Table 2 for both single and double pass. The number of trays shown on the drawings is eight with service as shown. This number can be varied according to the needs of the test program.

The tray spacing of twice the minimum as given in drawing number 84144001 will assure that tray spacing is not 1 imiting throughput and that the highest throughput is achieved consistent with other requirements. The minimum tray spacing will provide experimental data that will assist in determining the flooding mechanism.

\section{Test Operations}

The principle objective is to demonstrate the reduction in dissolbed working fluid that can be achieved with the use of a column designed for the purpose. The recommended column design and operating conditions for this purpose are given in Wahl Company Drawings 84144001 and 84144003 and the final report on the conceptual design study. Because of the uncertainty in the heat and mass tranfer models a set of experiments for different hole velocities and hole diameters, as well as hole spacing and mixing on the tray, should be run to allow extension of and increased confidence in these models. Because of the lack of flooding correlations and models for partially vaporized working fluid flow, a set of experiments for different tray configurations is recommended to provide a basis for these models and correlations. The hydraulic efficiency of the trays and the transfer- of working fluid and heat will be more easily interpreted the experimental results if the calumn operation is not dominated by a section with low temperature differences. Therefore the DCHE column should be tested with less than the optimum number of trays. This will make it possible to better analyse the experimental data, and interpret the results. It has been repeatedly

demonstrated that the sieve tray columns, with a sufficient 
number of trays, have a pinch temperature difference approaching zero, so that it should not be of concern in studying the effect of mass transfer and hydraulics.

\section{Model Development for Interpreting Results}

Further development of the theory will result in the ability to better interpret experimental results, to better size and predict the performance of the existing design, to assist in the development of new conceptual designs, and to predict performance of commercial size units. The theoretical aspects that are relatively easily developed and would be particularly beneficial are:

- regarding heat and mass transfer:

1. development of the integrated and discrete models to use an exposure time and an effective area which correctly accounts for interaction between jet and drop streams from adjacent holes, and to account for bulk (low energy turbulent) mixing.

2. development of the upflow flooding 1 imit model and the associated reduction in effective area due to interaction.

3. development of a mathematical model for predicting heat and mass transfer for a geothermal fluid dispersed, working fluid filled column.

- regarding flooding and hydraulic design methodalogy:

1. development of a downcomer flooding correlation to predict the effect of working fluid flow rate and percent vaporization on mass flooding for mixed fluids. The development would be based on the concept described in the section on "Downcomer Flooding" and will involve upflow-flooding mechanism combined with conventional downcomer flooding.

2. development of hydraulic design methodology for heating and boiling in a geothermal direct contact heat exchanger. This is necessary because it is a special application and has different operating conditions and purpose from that of mass transfer applications with which the literature deals and for which the literature correlations apply. This involves mainly the documentation of procedures and models we are using together. with calculations and refrences to substantiate their validity. 


\section{REFERENCES}

1. B. A. Sackett, F. B. Boucher and E. F. Wahl, Prel iminary Design Modifications to the EG\&G, Idaho, Inc Direct Contact Heat Exchanger for Achieving near Zero Working Fluid Losses, Wahl Company, October 1981.

2. R. H. Perry and C. H. Chilton, Chemical Engineers" Handbook, Fifth Edition, New York, McGraw Hil1, 1973.

3. B. J. Meister and G. F. Scheele, "Drop Formation from Immiscible Liquid Systems," AIChE J., 15, 1969, pp 700-706.

4. G. L. Mines, Q. J. DeMuth, and D. J. Wiggins, Thermal and Hydraulic Performance Tests of a SieveTray Direct-Contact Heat Exchanger Vaporizing Pure and Mixed-Hydrocarbon Rankin Cycle Working Fluids, EGG-2253, August, 1983.

5. E. F. Wahl and F. B. Boucher, Theory and Practice of Near Critical Pressure Direct Contact Heat Exchange, SAN/1076-1,1977.

6. E. F. Wahl, Geothermal Energy Utilization, New York, Wiley-Interscience.

7. R. E. Treybal, Mass Transfer Dperations, New York, McGraw Hill, 1980. 


\section{APPENDIX A. MODIFICATIONS TO THE DISCRETE REGION MODEL}

To extend the mathmatical model developed under the prior contract (see Reference 1) to cover conditions of importance to this project, the following modifications were made. To account for reduced heat and mass transfer in all regions due to interaction, the overall scaling factor Bo was added which scales all heat and transfer coefficients by this number. That is

h(corrected $)=$ BO $* h$

where

$n$ = heat or mass transfer coefficient in each region.

The time spent in the jet region was corrected to account for a tapered jet. That is

$t_{j}=\left(L_{j} / \mathrm{Ln}_{n}\right)\left[2 \mathrm{D}_{n} /\left(\mathrm{D}_{j}+\mathrm{D}_{\mathrm{n}}\right)\right]$

where

$$
\begin{aligned}
& \mathrm{t}_{j}=\text { time in jet region } \\
& \mathrm{L}_{j}=\text { length of } j \text { et } \\
& \mathrm{un}_{\mathrm{n}}=\text { hole velocity } \\
& \mathrm{D}_{j}=\text { diameter of jet }
\end{aligned}
$$

rather than

$\mathrm{t}_{j}=\mathrm{L}_{\mathrm{j}} / \mathrm{Ln}$

as formerly.

As drops become large and distorted, the terminal velocity decreases. Treybal's correlations do not worl: well for large diameters. Therefore the terminal velocity calculation was modified to be independant of drop diameter $D$ at large $D$ by

Ut $($ corrected $)=U t /(1+D) 9.5$ $(A-3)$

where 
Ut = terminal velocity of a drop

Since Ut is proportional to $D$, the corrected value of Ut approaches a constant as $D$ approaches infinity.

The data of Meister (see Fieference 2 ) shows that the velacity Unj at which jetting starts is given by

$u_{n j}=\left(40 / D H_{H}\right) 0.5$

The model was modified to use this Equation.

Drop prediction by prior methods in the literature could not be used because the drop size as well as the maximum hole velocity were not reasonable(1). The data of Scheele and Meister can be correlated by

$\mathrm{D}=6\left(5^{\circ} / 5\right)^{0.2}\left\{\left\{7+37.227\left(\mathrm{~V} / \mathrm{V}^{3}\right) \exp \left[(-5.3350 \mathrm{D})-\{(\mathrm{Ln}-32) / 4 \mathrm{c}\}^{2}\right]\right\}_{(\mathrm{A}-6)}\right.$

where

$$
\begin{aligned}
& D=\text { drop diameter, cm } \\
& D_{n}=\text { hole diameter, cm } \\
& \text { Un }=\text { hole velocity, cm/sec } \\
& S^{\prime}=\text { surface tension } \\
& S^{*}=\text { surface tension at } 25 \mathrm{c} \\
& v=\text { viscosity, dynes/cm } \\
& v^{*}=\text { viscasity at } 25 \mathrm{c}
\end{aligned}
$$

Values of drop diameter calculated by this equation are shown in Table B-1 for varicus hole diameters and a temperature of $25 \mathrm{C}$. 
TABLE A-1 DROP SIZE PREDICTION BY CORRELATING EQUATION A-I

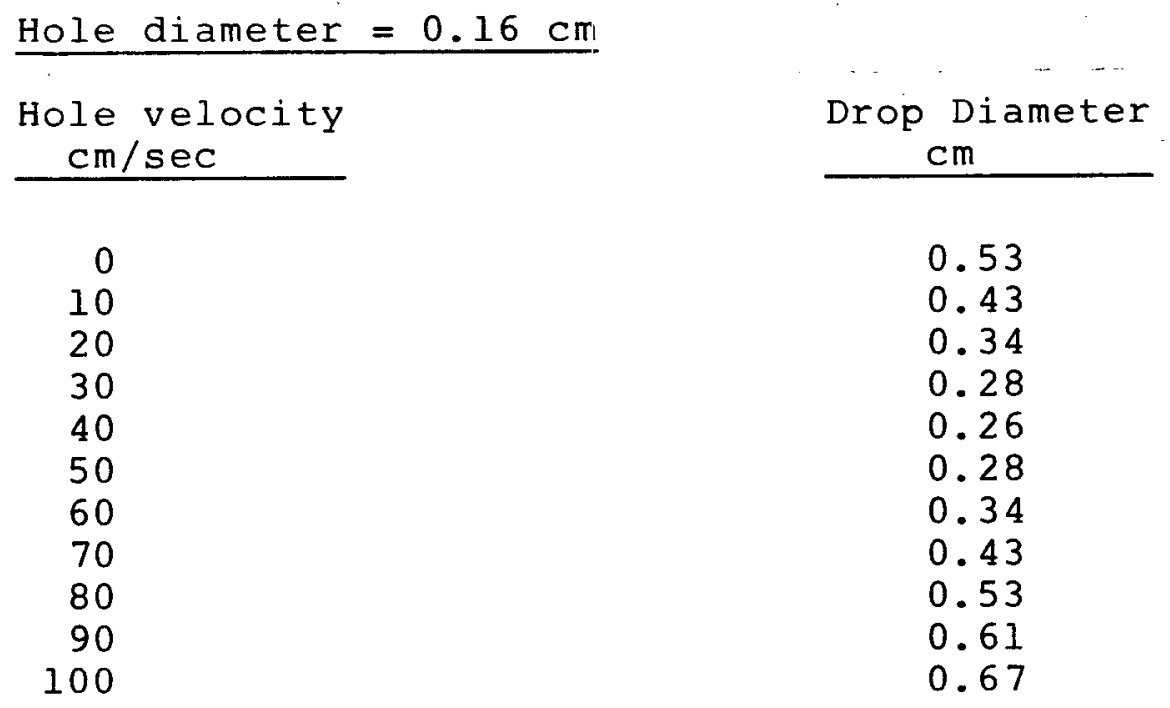

Hole diameter $=0.254 \mathrm{~cm}$

$\begin{array}{rr}0 & 0.58 \\ 10 & 0.50 \\ 20 & 0.43 \\ 30 & 0.38 \\ 40 & 0.36 \\ 50 & 0.38 \\ 60 & 0.43 \\ 70 & 0.51 \\ 80 & 0.58 \\ 90 & 0.64 \\ 100 & 0.69\end{array}$




\section{AFFENDIX B. ANALYSES DF HEAT AND MASS TRANSFEF}

Two methods of determining the mass transferred to the geothermal fluid in a direct contact heat exchanger were developed in the prior worl: (see Reference 1). One method of analysis uses the discrete region model and the other uses the integrated region model. The former is a model of heat and mass transfer for a jet, a drop formation, and a drop rising region (Figure 1). This is the classic description for the mechanism of transfer when one fluid is dispersed into another by flow through a hole. The second method, the integrated model lumps the individual transfer mechanism into one region in which heat and mass are transferred by convection in the bulk of the fluid and by conduction through a stagnant boundary layer at the transfer interface. Due to interaction the actual mechanism of transfer is more complex than that of the discrete region model. Thus the integrated model with parameters experimentally correlated may be better for predicting behavior than the discrete model.

The analysis for the discrete model was modified as described in Appendix $A$ to extend its range of application to cover the hole velocities, diameters, temperatures, and fluid properties of interest in this conceptual design study. Then the analyses were run and adjusted 50 the predictions matched the experimental data takeri at faft River (4).

These analyses which predict the fiaft fiiver data were then Fun for a large variety of hole sizes, hole velocities, tray spacings, fraction bubbling open area, and number of trays to arrive at optinum design values. In this case the optimum is a mininimum dissolved concentration of worting fluid in the outlet geothermal fluid for practical physical design conditicns foi the tray and for reasonable flowrates and accomplished temperature changes (heat transferred by the column?.

\section{Comparison of Fredictions with Experimental Data}

The analyses were run for the tray configuration and operating conditions for selected runs of the Faft River tests. The temperature data taken from the report by Mines et al (see Fieference 4) which was used to test the models is shown in Table E-1. 
TABLE B-1 EXPERIMENTAL TEMPERATURES USED FOR TESTING THE MODELS

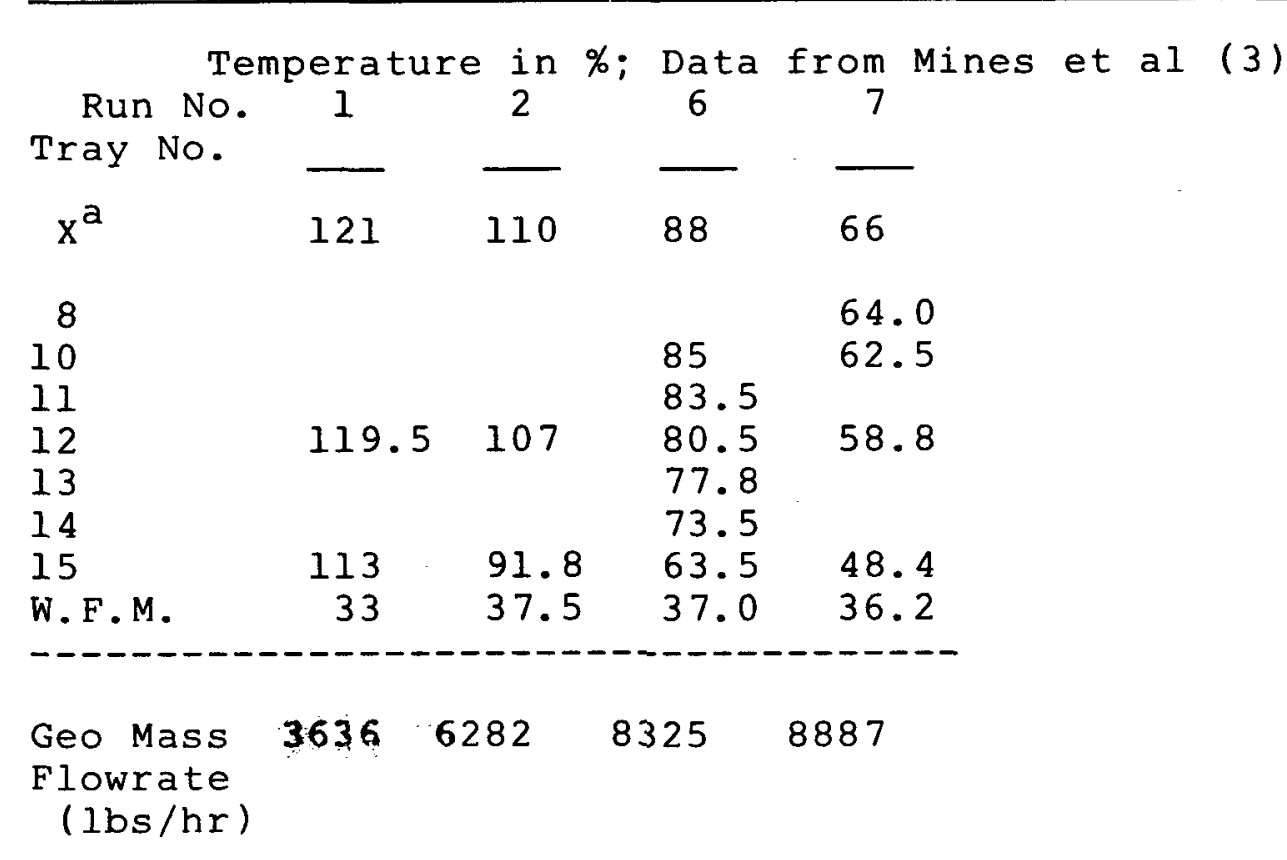

a. The geothermal fluid inlet temperature to the top of the liquid/liquid preheating section. 
Discrete Fegion Model

The temperatures predicted by the discrete model are shown in Table B-2. In adjusting the model to match the experimental data an overall scaling factor BO was used. This was set at 0.29 to match the data. This gave plate efficiencies of 0.75 to 0.79 which is somewhat higher than that determined by Mines et al (see Reference 4). The effect of dropping Bo to 0.25 has a negligible effect on the predicted concentration of dissolved working fluid. In a test case it varied from 37.4 to $37.8 \mathrm{ppm}$.

\section{Integrated Model}

The integrated model contains three unknown parameters, the effective area, the time of exposure, and the effective boundary 1 ayer thickness. These were adjusted to match the experimental data.

More than one set of parameters could be used to match the data, so that the relative values of these parameters was not established. The results of computer runs for various tray design parameters showed little effect on the dissolved working fluid. This is because the prediction of the model is dominated incorrectly by the time factor which is calculated assuming no interaction between jets and associated bubbles. Design changes; which result in increased convective transfer and decreased conductive transfer will decrease the mass transfer for a given heat transfer as shown in the prior work. This model can be further developed to predict the effect by correctly calculating the exposure time and effective area and then deternining the effective boundary layer thickness by matching experimental data. This must be done by including the interaction of jets which has not yet been completed.

The predictions of the integrated model are shown in Table $\mathrm{B}-3$. The effective area was assumed to be the area calculated by the discrete region model multiplied by an area factor. The effective boundary layer thickness was adjusted for a given area factor to match the experimental data. The results were:

$$
\begin{array}{ll}
\text { area factor } & =1.0 \\
\text { boundary layer thickness } & =0.074 \mathrm{~cm} .
\end{array}
$$

The effective boundary layer thickness of $0.074 \mathrm{~cm}$ is quite large compared to what would be expected. However the use of this makes the conditions for optimizing the 
TABLE B-2 GEOTHERMAL FLUID TEMPERATURES PREDICTED BY DISCRETE REGION MODEL FOR RAFT RIVER TEST CONDITIONS

\begin{tabular}{crccc}
\hline $\begin{array}{l}\text { Raft River } \\
\text { Run No. }\end{array}$ & 1 & 2 & 6 & 7 \\
Tray No. & & & & \\
\hline 8 & - & - & - & 64.6 \\
10 & - & - & 83.8 & 63.1 \\
11 & 119.8 & 107.2 & 81.1 & 60.2 \\
12 & - & - & 77.8 & - \\
13 & - & - & 72.6 & - \\
14 & 108.5 & 91.8 & 64.2 & 49.2 \\
15 & & & & \\
\hline
\end{tabular}


TABLE B -3 GEOTHERMAL FLUID TEMPERATURES PREDICTED BY INTEGRATED REGION MODEL FOR RAFT RIVER TEST CONDITIONS

\begin{tabular}{|c|c|c|c|c|}
\hline \multirow{2}{*}{$\begin{array}{l}\text { Tray } \\
\text { No. } \\
\end{array}$} & \multicolumn{3}{|c|}{ Raft River Run No. } & \multirow[b]{2}{*}{$\underline{7}$} \\
\hline & $\underline{\underline{1}}$ & $\underline{2}$ & $\underline{6}$ & \\
\hline 8 & - & - & - & 63.6 \\
\hline 10 & - & - & 83.4 & 61.3 \\
\hline 11 & - & - & 81.6 & - \\
\hline 12 & 120.3 & 107.5 & 79.1 & 57.8 \\
\hline 13 & - & - & 75.3 & - \\
\hline 14 & - & - & 68.5 & - \\
\hline 15 & 112.5 & 91.9 & 63.8 & 48.1 \\
\hline
\end{tabular}


design more severe because it penalizes the heat transfer. After the optimum was found, the boundary layer thickness and area factor wereadjusted to the more reasonable values of

$\begin{array}{ll}\text { area factor } & =0.25 \\ \text { boundary layer thickness } & =0.03 \mathrm{~cm}\end{array}$

to predict the expected concentration of working fluid in the outlet geothermal fluid.

\section{Design Conditions for Analysis}

Eecause most of the potential electrical generating capacity is achieved when the geothermal fluid is cooled to $180 \mathrm{~F}$ (BS $\mathrm{C}$ ) as shown in Tatie E-4, this temperature was chosen as the design outlet temperature. Since the mass transferred in the lower part of the column is generally insignificant, the minimum mass transfer condition is not sensitive to this variable. So a fixed outlet geothermal fluid temperature of $83 \mathrm{C}$ was used throughout.

The East Mesa Well b-2 temperature is $315 \mathrm{~F}$ ( $157 \mathrm{C}$ ). For a boiling isobutane working fluid, the boiling temperature will generally be $240 \mathrm{~F}(115 \mathrm{C})$ or lower. Consequently the preheating section of the column will operate from $104 \mathrm{~F}(40 \mathrm{C})$ to $240 \mathrm{~F}(115 \mathrm{C})$. For mixed fluids the boiling starts at a lower temperature in the column but is completed at a higher temperature. The models have not been developed for mixed fluids, consequently these conditions were examined only cursorily.

To summarize, the conditions that were used for determining optimimum hole size and velocity in the liquid/liquid preheating section were:

- geothermal fluid inilet temperature $120 \mathrm{C}$

- working fluid inlet temperature $40 \mathrm{C}$

- working fluid outlet temperature $115 \mathrm{C}$

\section{Dptimization}

Eecause of the complexity of the heat and mass transfer process which is modeled, the selection of tray design requires analysis of the mechanisms and of the various transport modes. These factors were analyzed and appropriate 
TABLE B-4. EFFECT OF GEOTHERMAL FLUID DISCHARGE TEMPERATURE ON ITS ELECTRICAL POWER POTENTIAL

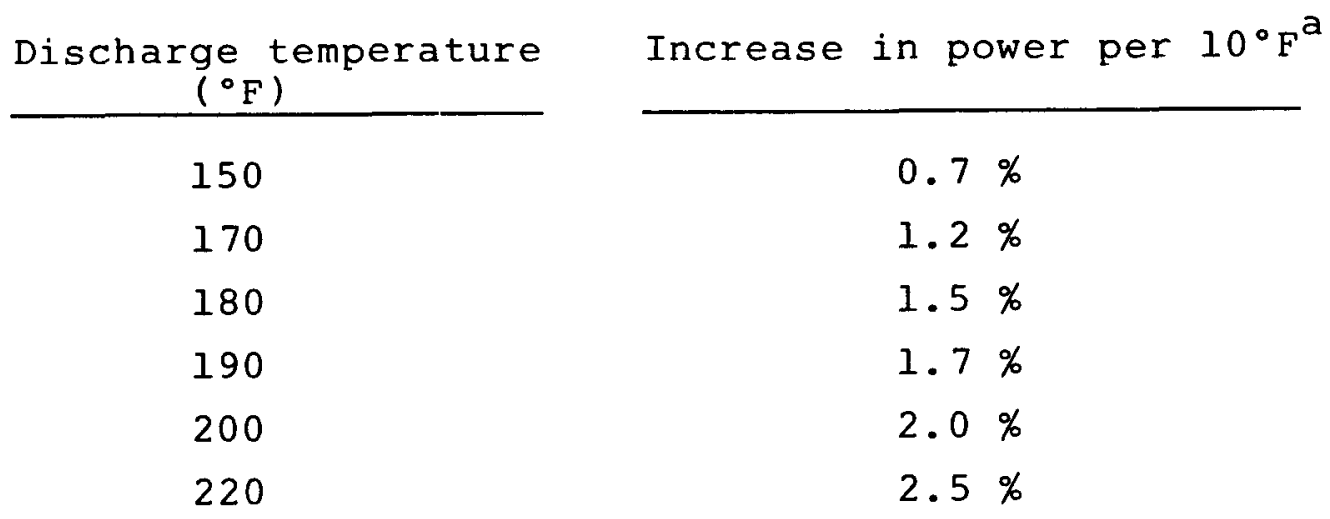

a. The percent increase in power potential at $50 \%$ efficiency for a $10^{\circ} \mathrm{F}$ redaction in geothermal fluid discharge temperature. 
changes made to arrive at optimum design configurations. Qver 200 computer runs were made to study the effect of the various variables in the region of interest.

These analyses covered columns that were a) geothermal fluid filled, working fluid

dispersed; b, working fluid filled, light fluid dispersed; and $c$, working fluid filled, geothermal fluid dispersed.

\section{Fiesults}

The results with regard to minimizing total working fluid dissolved in the geothermal fluid from analysis of the runs are as follows. All results are from the discrete region model analysis except where otherwise stated.

1. The drop formation region shows the largest ratio of heat to mass transferred, being 3 to 10 times better than the other regions as shown in Table B-5. The explanation for this is that the jet region is plug flow with conductive transfer dominating, the formation region is convective transfer, and the drop rising region is a mixture of the two. The models for these transfer mechanisms were developed in our prior worl: (see Reference 1).

2. The dissolved working fluid is proportional to the transfer length Ltr as shown in Figure $\mathrm{B}-1$. The transfer length is the sum of the lengths of each of the three regions as shown in Figure 1 .

3. Additional downcomer length required for $10 \%$ additional flow capacity to handle the deeper coalesced layer may increase the transfer length 3 to $7 \mathrm{~cm}$ and increase the dissolved working fluid 4.5 ppm at design operating conditions.

4. Flate thermal efficiences 1 ess than $70 \%$ and preferably less than 50\%, however achieved, will maximize heat transferred while minimizing mass transferred. This is due to the rapid transfer of heat relative to mass transfer which results in rate of heat transfer declining before the mass rate of transfer declines.

5. There are two approaches to optimizing the tray design. One is to use a low hole velocity to achieve a short jet and a short drop rising length. This maximizes the use of the drop formation region which has the highest temperature change for a given mass concentration 
TABLE B-5. RATIO OF TEMPERATURE CHANGE TO CONCENTRATION CHANGE IN VARIOUS TRANSFER REGIONS AT NEAR OPTIMUM OPERATING CONDITIONS.

\begin{tabular}{|c|c|c|}
\hline \multirow{2}{*}{ Region } & \multicolumn{2}{|c|}{ (Temperatüre change)/(concentration change) } \\
\hline & Top ptatef(115 c) & Mid-lower plate $(100 \mathrm{C})$ \\
\hline jet & 3 t:o 4 & 35 \\
\hline formation & 26 to 35 & 300 \\
\hline drop rise & 13 to 20 & 90 \\
\hline
\end{tabular}




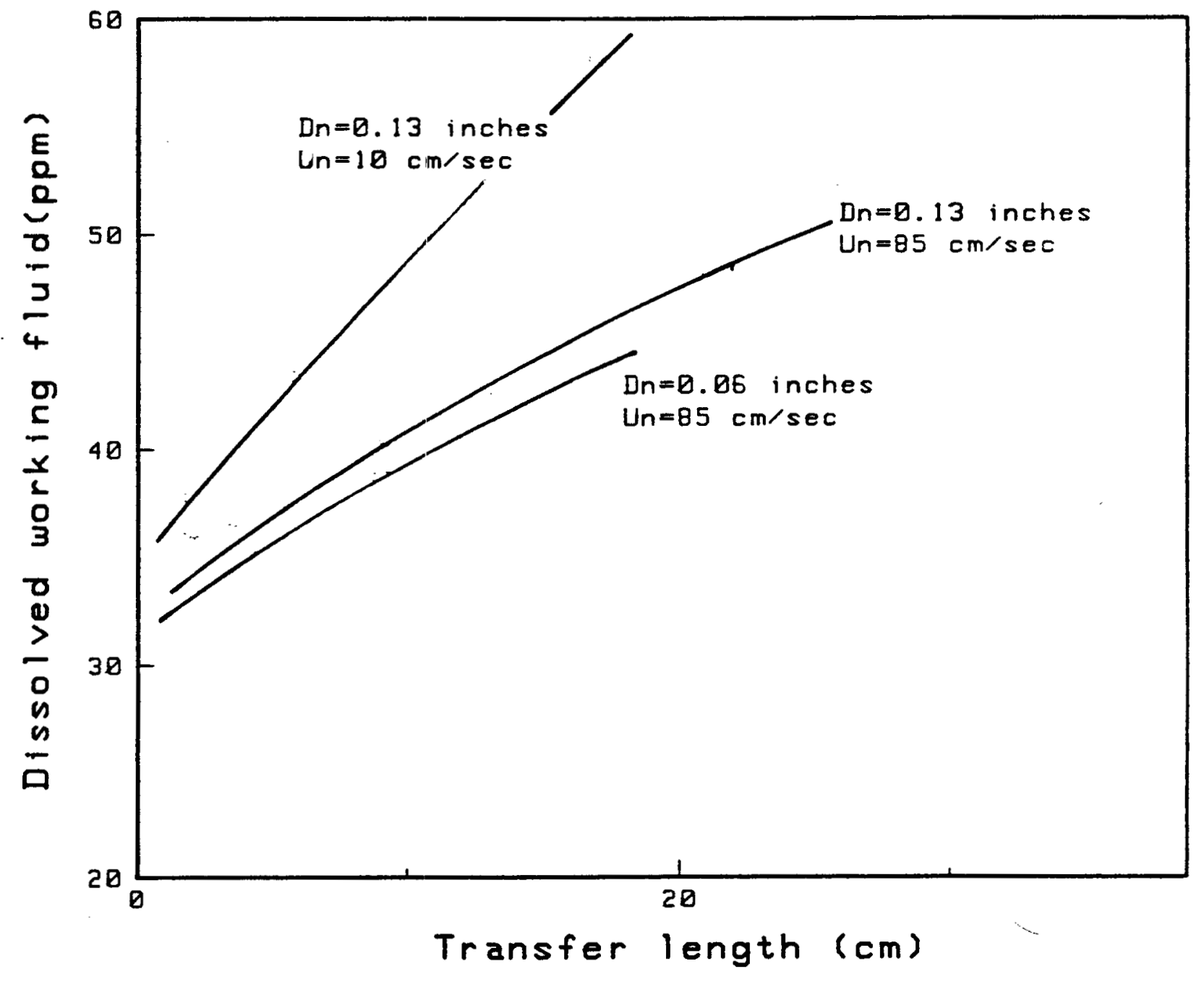

Figure B-l. Effect of transfer length on dissolved working fluid. 
change (see result 1 above). The other approach is to use a very high hole velocity with a 1 imited jet length which also maximizes the heat transferred relative to the mass transferred. Figure $B-2$ shows the decreasing mass transfer at both high and low hole velocities.

b. For constant transfer distance Ltr of the working fluid through the geothermal fluid, the optimum hole diameter Dn and velocity Un is a broad $f 1$ at minimum and a good optimum can be found over a range of hole diameters. Figure B-3 through B-5 show the dissolved worling fluid concentration plotted versus hole velocity and nozzle diameter for various values of the heat and mass transfer exponent. Examination of these figures shows that a hole diameter of 0.25 inches and a velocity of 40 to $50 \mathrm{~cm} / 5 \mathrm{cc}$ gives a good optimum. Although larger velocities give a lower dissolved concentration, these gains may not be realised in practice. One reason is that the transfer length would have to increase to allow for separation of the fluids and for a larger variation in the coalesced layer.

7. Fesults from analysis of computer runs using the integrated region model are as follows.

a. The concentration is minimized by large hole diameters as shown in Figure $B-5$ and by hale velacities of of 25 to $40 \mathrm{~cm} / \mathrm{sec}$ depending on hole diameter.

b. A good optimum hole diameter is 0.25 inches with a hole velocity of 40 to $50 \mathrm{~cm} / \mathrm{sec}$ (Figure $\mathrm{B}-6$ ).

c. A 50\% decrease in laminar layer thickness and effective area decreases the dissolved working fluid $15 \%$.

8. Fesults for a working fluid filleds geothermal fluid dispersed columi are as follows.

a. The concentration of working fluid dissolved in the outlet gecthermal fluid is relatively insensitive to the design and operating conditions.

b. The outlet concentration is generally about $42 \mathrm{ppm}$ which compares favorably with the 38 ppm for the geothermal fluid filled, working fluid dispersed case with the same parameters in the model.

c. A hole diameter of 0.25 inches gives a $f$ lat response over a large range of hole velocity and gives 


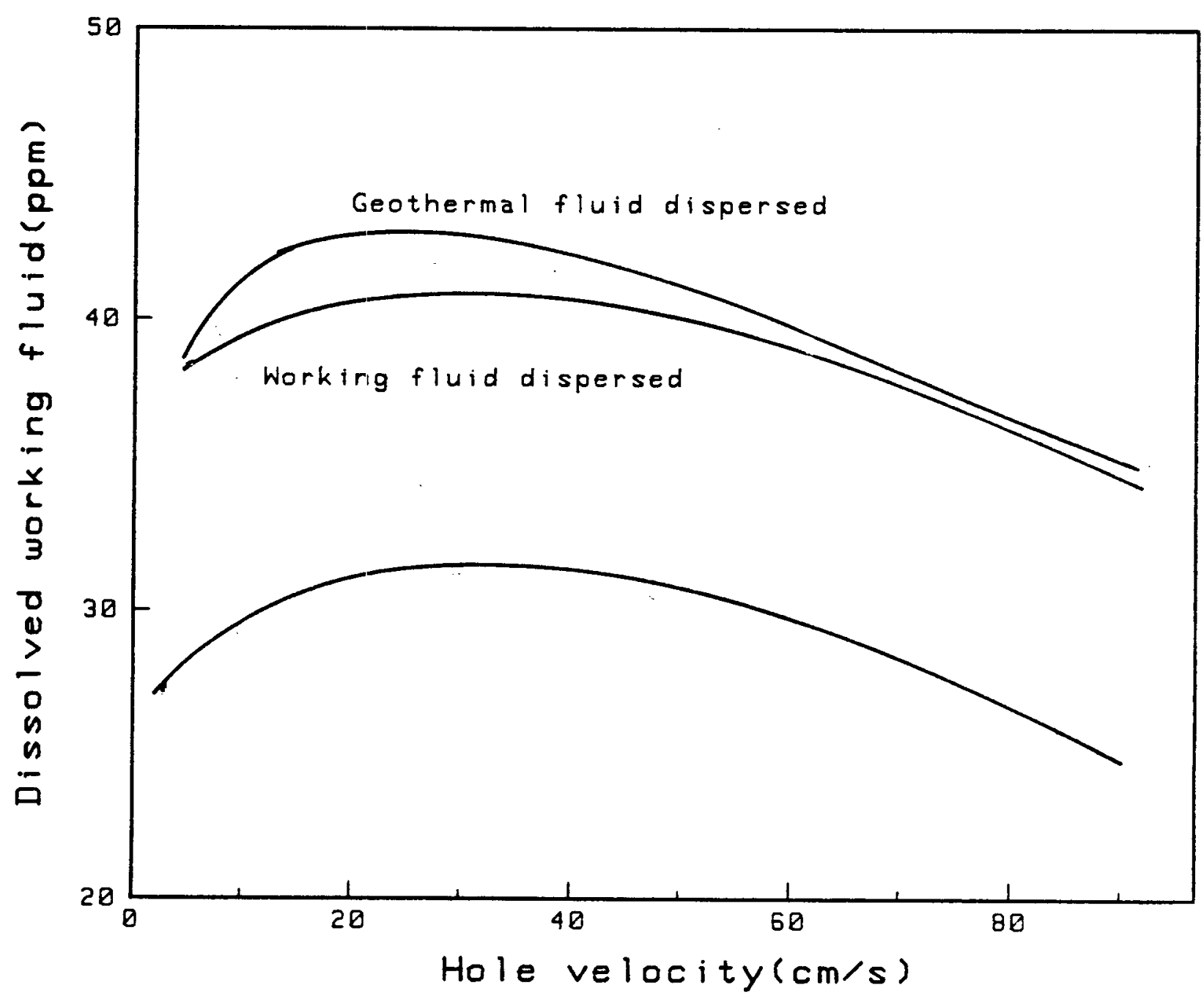

Figure B-2. Effect of high and low velocity on dissolved working fluid concentration for a 0.13 inch diameter hole. 

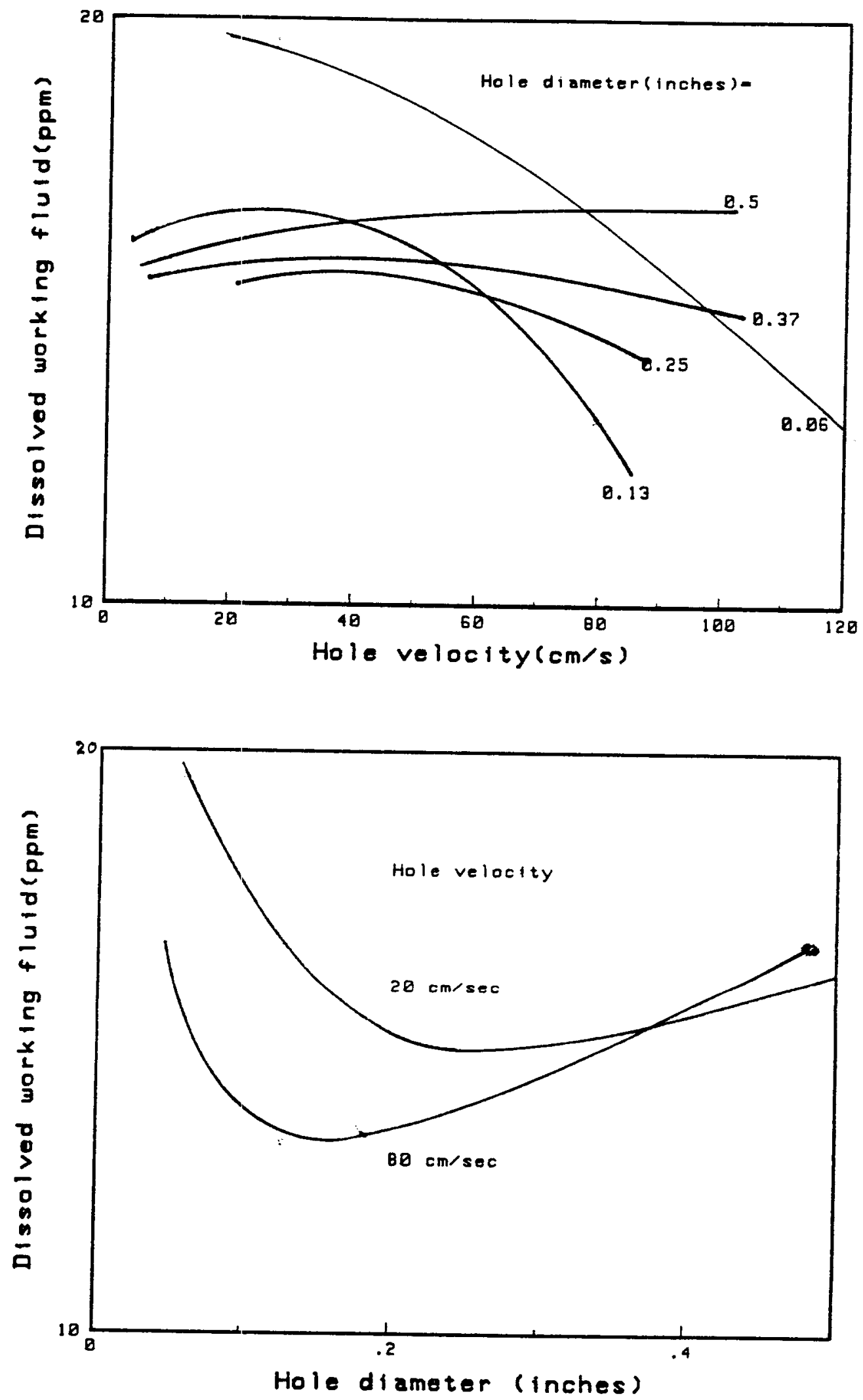

Figure B-3. Effect of (a) hole velocity and (b) hole diameter on dissolved working fluid concentration predicted by discrete model, heat and mass transfer analogy exponent $=.20 .57-$ 

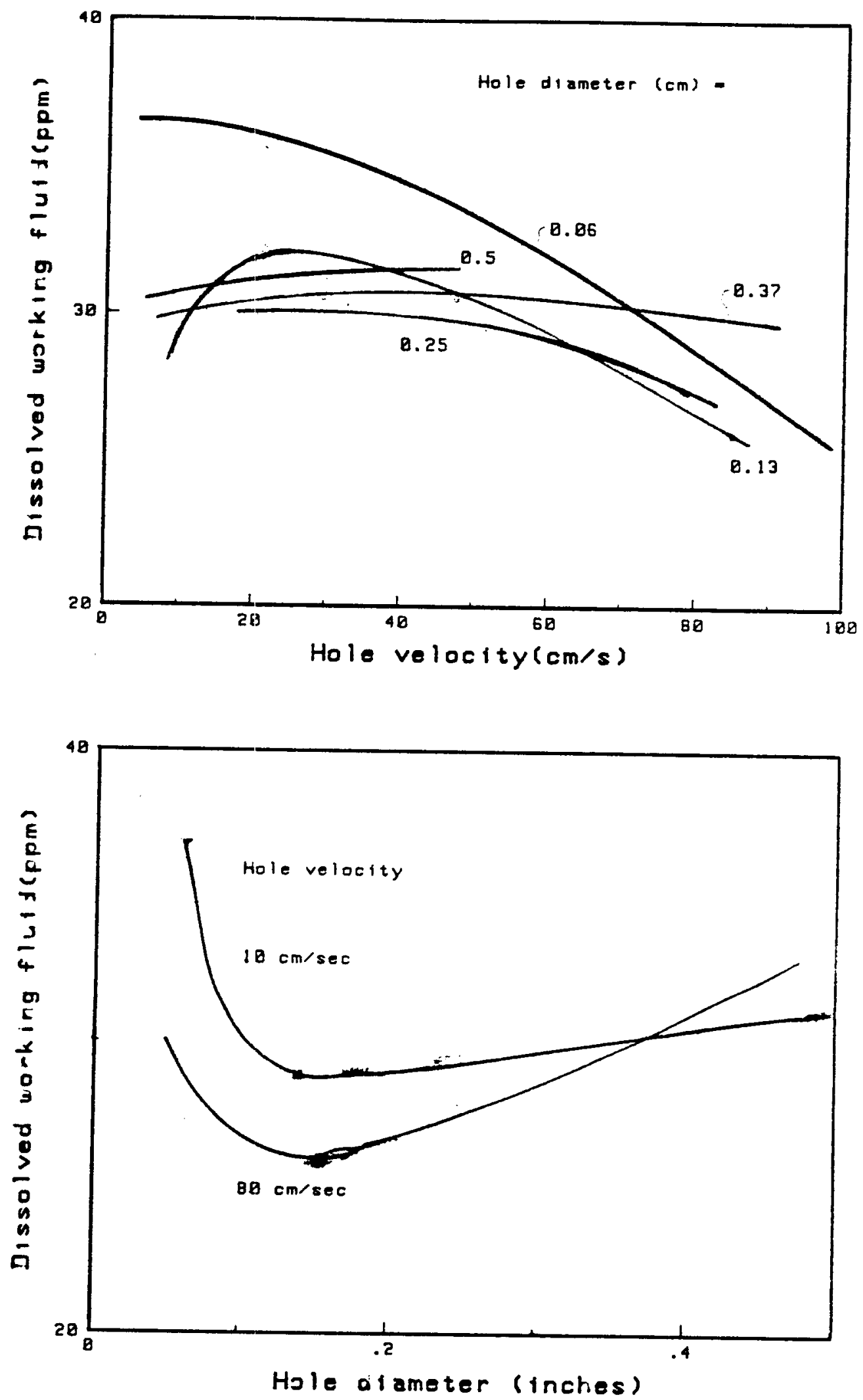

Figure B-4. Effect of (a) hole velocity and (b) hole diameter on dissolved working fluid concentration predicted by discrete model, heat and mass transfer analogy exponent $=.24$. 

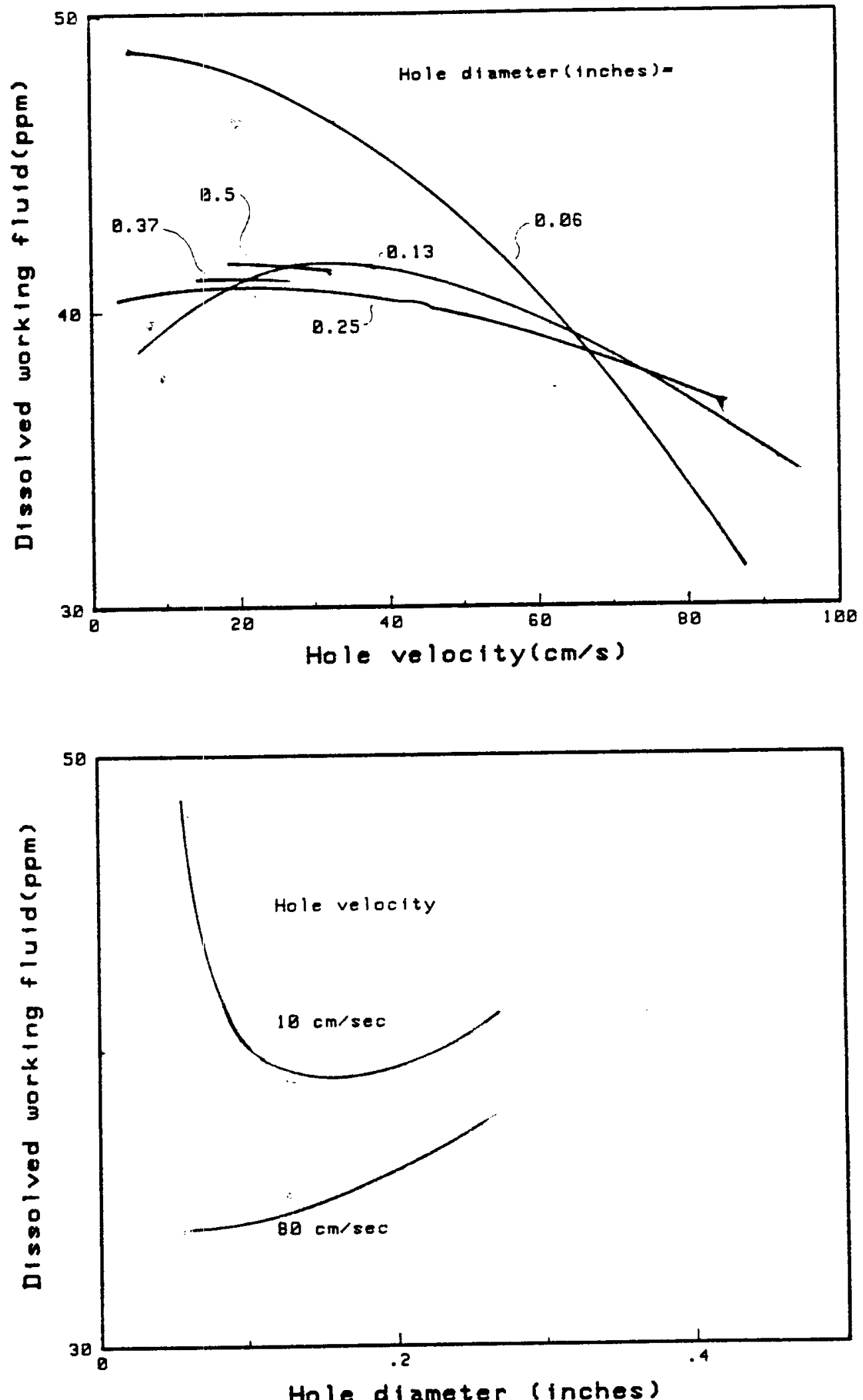

Figure B-5. Effect of (a) hole velocity and (b) hole diameter on dissolved working fluid concentration predicted by discrete model, heat and mass transfer analogy exponent $=.33$. $-59-$ 


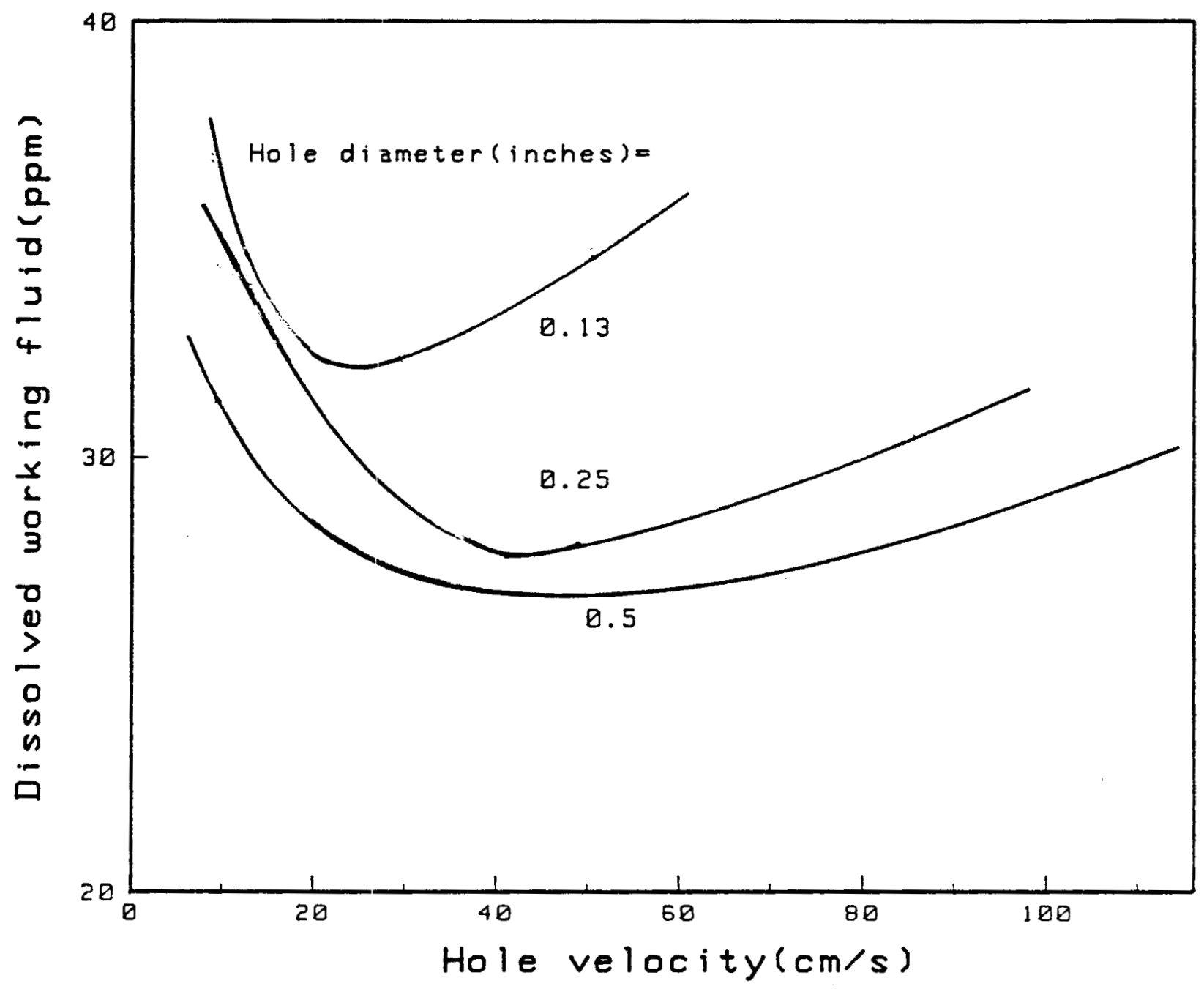

Figure B-6. Dissolved working fluid concentration predicted by the integrated region model for an area factor of 1.0 . 


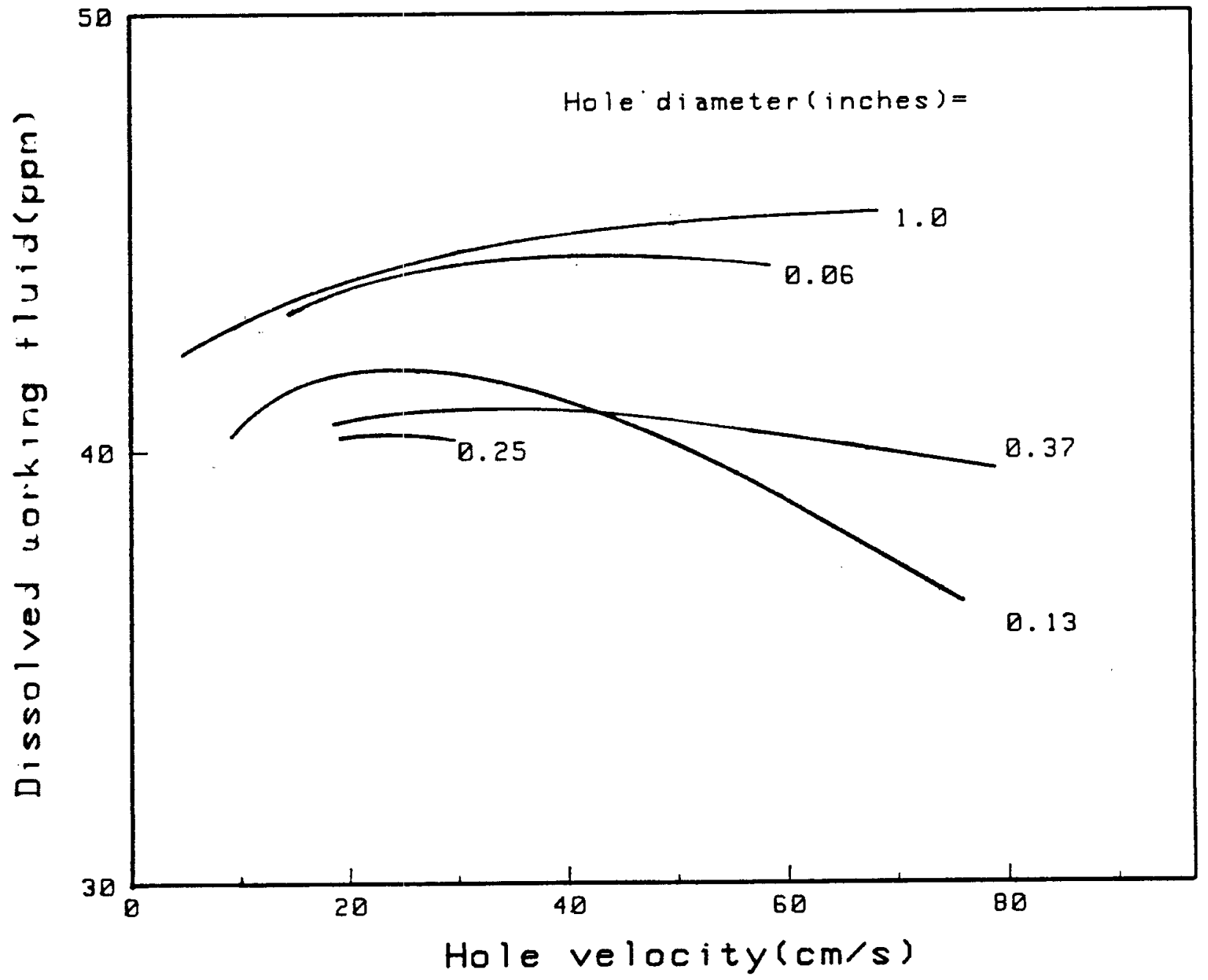

Figure B-7. Dissolved working fluid concentration predicted by the discrete region model for a geothermal fluid dispersed column. 


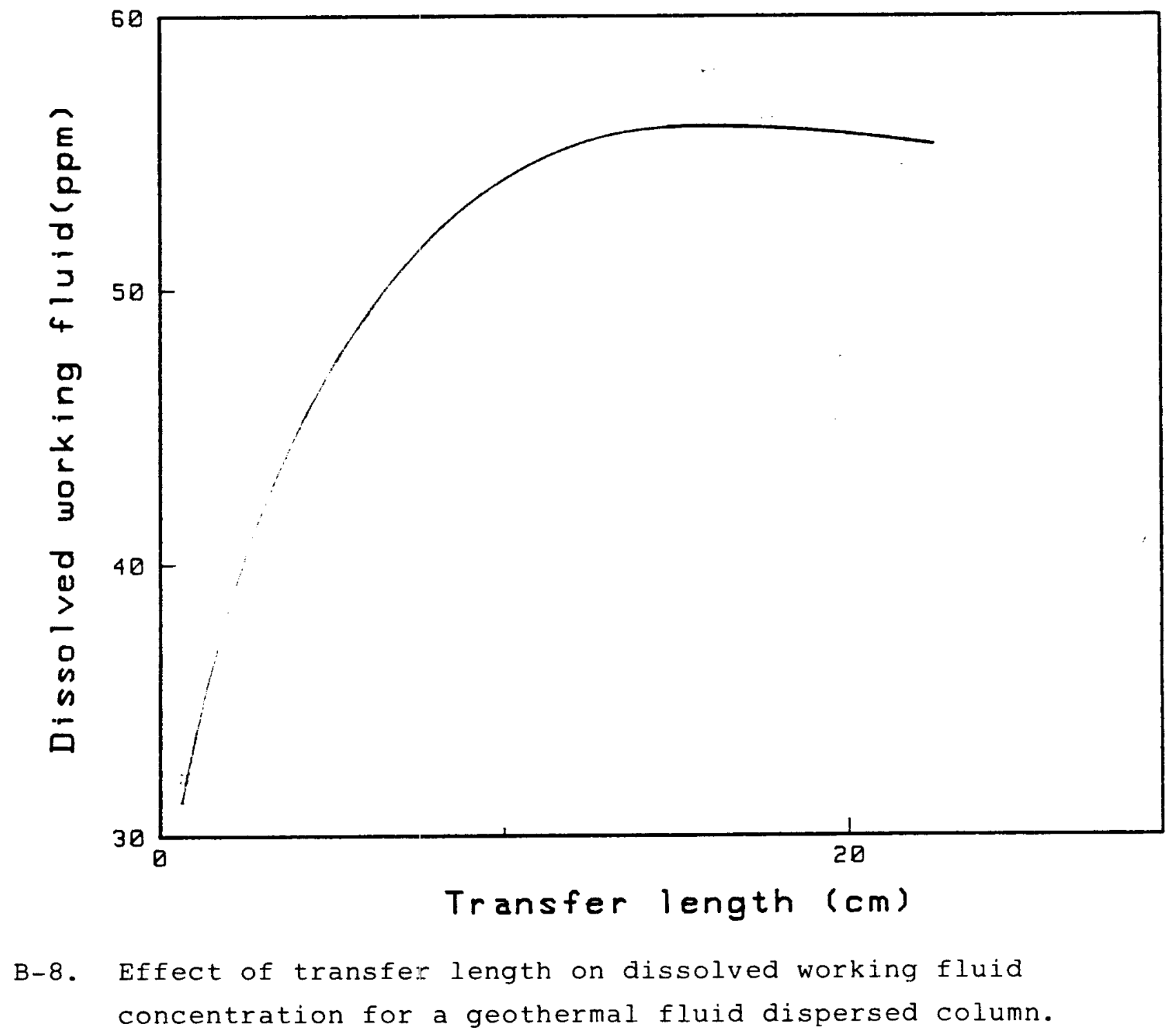


minimum dissolved worling fluid at a velgcity of $40 \mathrm{~cm} / \mathrm{sec}$ (Figure E-T). At very high and very low Un, a small 1 hole such as 0.13 inches gives a lower dissalved working fluid, but for practical purposes the 0.25 hole would be best.

9. The effect of mixing is to decrease the effective area factor and boundary 1 ayer thickness in the integrated model and to decrease the heat and mass transfer analogy exponent (1) in the discrete model. The effect of this is shown in Figures $\mathrm{E}-\mathrm{G}$ and $\mathrm{E}-10$.

The area factor is decreased because the mixing will increase the amount of interaction between rising fluid streams resulting in a decrease in effective area. The heat and mass transfer exponent is decreased because the increased mixing causes a larger amount of transfer by convective mixing. As shown previously(1), this exponent varies from 0.5 for pure conductive transfer to 0.2 for pure corivective transfer.

10. Boiling or vapor formation results in increased worling fluid volumetric rate so that at constant hole velocity the geothermal mass flow rate decreases per hole. Since surface area per hole is constant, the mass transfer rate is constant, but much greater per unit mass of geothermal fluid. This would result in greater concentrations of dissolved worling fluid. However as vapor portion increases, hole velocity should increase so that the geothermal fluid mass flow rate per hole remains constant. Table $B-6$ shows that for $1 \%$ vaporization the dissolved working fluid is approximately the same as for no vaporization.

\section{Conclusions}

In consquence of the above results, the trays should be designed with minimum transfer distance Ltr. Although the low hole velocity approach may have some design advantages, the high velocity approach will result in increased turbulence and $\mathrm{mixing}$ and therefore the convective component of the transfer. Also the formation region would be larger al though this is not included in the model. The effect of increased turbulence and mixing is to decrease the laminar layer thicleness and the effective interface area due to coalescence assuming that the holes are in proximity to one another. This results in lower concentration of dissolved working fluid. 


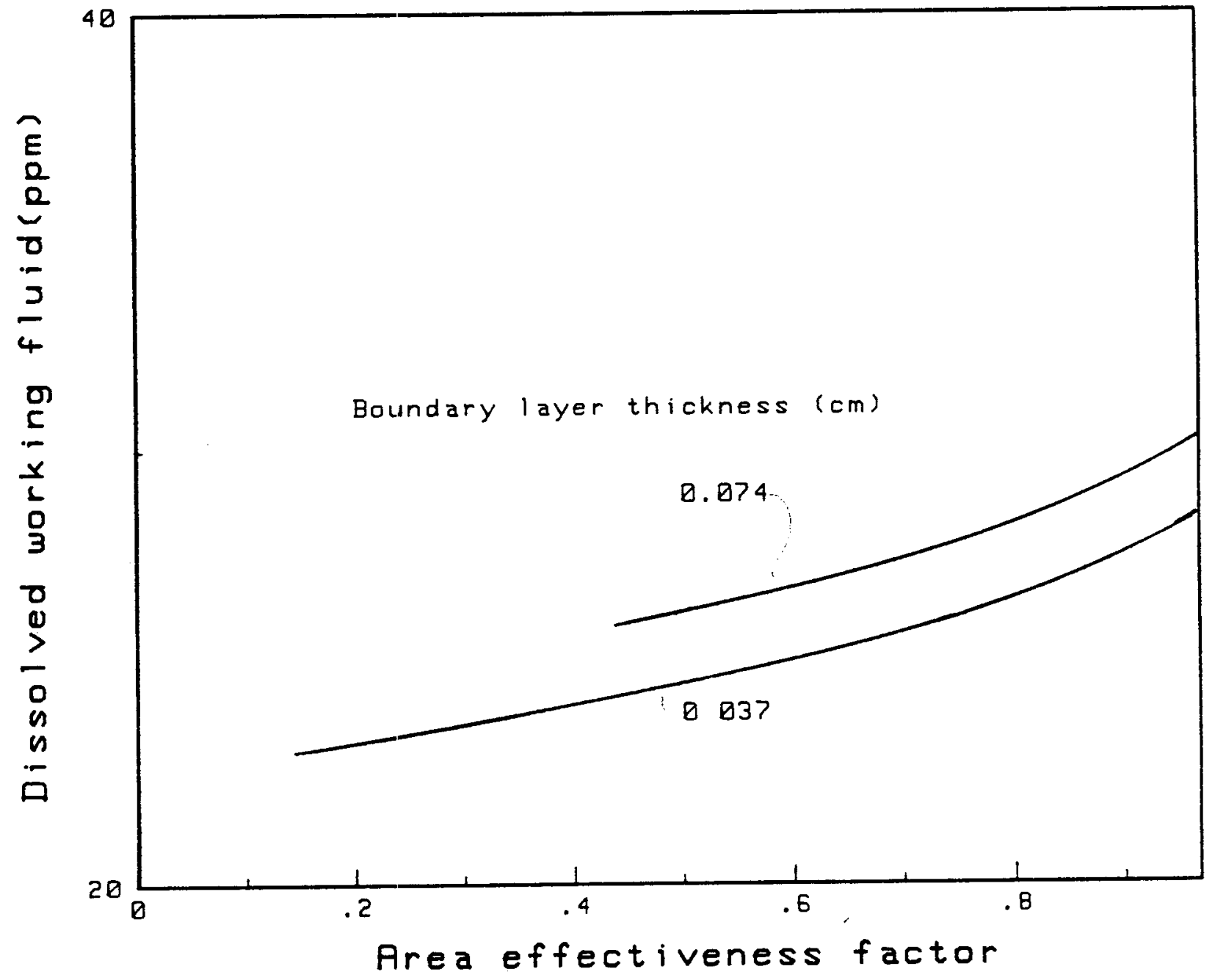

B-9. Effect of mixing (low area factor) and boundary layer thickness on working fluid concentration shown by concentration versus area factor at various boundary layer thicknesses precidted by integrated model. 


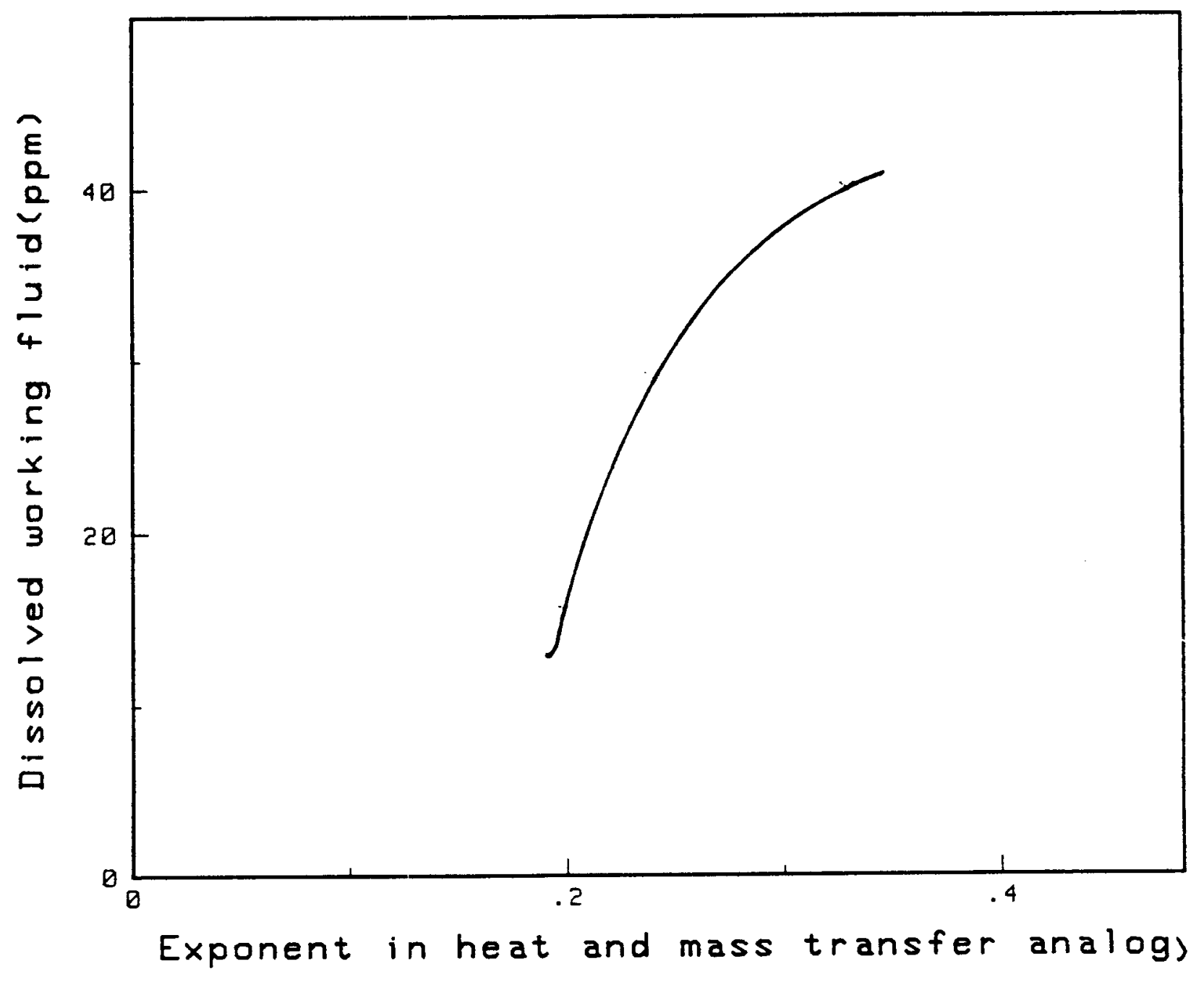

Figure B-10. Effect of mixing (low exponent) on working fluid concentration shown by concentration versus exponent predicted by discrete model. 

TAELE B-6 DISSOLVED WORKING FLUID WITH AND WITHOUT VAPORIZATION DROPPING GEOTHERMAL FLUID TEMPERATURE FROM $120^{\circ} \mathrm{C}$ to $84^{\circ} \mathrm{C}$

\begin{tabular}{|c|c|c|c|}
\hline \multirow[b]{2}{*}{$\begin{array}{l}\text { WF } \\
\text { Outlet }\end{array}$} & & \multicolumn{2}{|c|}{$\begin{array}{l}\text { Un }=80-90 \\
\text { Dn }=0.13 \\
\end{array}$} \\
\hline & & $\begin{array}{l}\text { WF } \\
\text { Inlet }\end{array}$ & $\begin{array}{l}\text { Outlet } \\
\text { PPM } \\
\end{array}$ \\
\hline 111.8 & $\begin{array}{l}\text { No vaporization, constant } \\
\text { nozzle velocity. }\end{array}$ & 37.8 & 40.7 \\
\hline 111.8 & $\begin{array}{l}1 \% \text { vaporization, constant } \\
\text { nozzle velocity. }\end{array}$ & 43 & 51.9 \\
\hline & $\begin{array}{l}\text { l\% vaporization, constant } \\
\text { mass flow/nozzle }\end{array}$ & 40 & 43.6 \\
\hline
\end{tabular}

a. Also approximately constant mass flow/nozzle. 